\title{
Designing dynamic reverse logistics network for post-sale service
}

\author{
Shraddha Mishra ${ }^{1} \cdot$ Surya Prakash Singh ${ }^{1}$ \\ Published online: 8 July 2020 \\ (c) Springer Science+Business Media, LLC, part of Springer Nature 2020
}

\begin{abstract}
The paper addresses the problem of designing a multi-country production-distribution network that also provides services such as repairs and remanufacturing. The proposed work concentrates primarily on post-sale service provided by the firm under warranty returns. The proposed model assumes that existing warehouses can also serve as collection centres or repair centres for reverse logistics. In addition, the model also explores the possibility of establishing a new facility. Hybrid facilities are considered because of their huge cost-cutting potential due to equipment sharing and space sharing. The capacity of hybrid facilities can be expanded to a predefined limit to process returned products without hampering forward logistics operations. However, if a product cannot be repaired at the warehouse, it is transported to the plant for remanufacturing. The model optimizes the overall configuration and operation cost of the production-distribution network. The production-distribution model developed in the paper is a mixed-integer nonlinear program (MINLP) that is later transformed to a mixed-integer linear program to reduce the solution time. The usefulness of the model is illustrated using a randomly generated dataset. The model identifies (a) the optimal locations/allocations of the existing/new facilities, (b) the distribution of returned products for refurbishing and remanufacturing, and (c) the capacity expansion of the existing plants and warehouses to facilitate remanufacturing and repair services.
\end{abstract}

Keywords Refurbishing $\cdot$ Remanufacturing $\cdot$ Facility network $\cdot$ Mixed-integer nonlinear program (MINLP)

\section{Introduction}

The rapid rise of e-commerce and the emergence of the Internet of Things (IoT) have provided a wide range of varieties to customers at just one click. When purchasing a product, customers not only focus on the product's quality but also are concerned with the post-sale

Surya Prakash Singh

surya.singh@gmail.com

Shraddha Mishra

Shradhamishra625@gmail.com

1 Department of Management Studies, Indian Institute of Technology Delhi, New Delhi, India 
services provided by product manufacturers. In addition to customer satisfaction, there exist a variety of environmental, economic, and legislative reasons that have made companies more accountable to customers for products post-sale (Du and Evans 2008). For instance, extended producer responsibility (EPR) and waste electrical and electronic equipment (WEEE) have imposed legal obligations on original equipment manufacturers (OEMs) for the safe handling and disposal of end-of-life products (Nnorom and Osibanjo 2008). In addition, the current global economy, the rapid development in technology and the evolution of e-commerce have increased consumerism and consequently increased the demand for new products. These factors have increased the consumption of raw material, reduced the life cycle of products, and increased the generation of waste. Therefore, the lack of raw materials and environmental issues made the incorporation of reverse logistics into the supply chain network necessary. Given the increasing environmental consciousness, the paradigm shift from a linear economy to a circular economy is required with a greater focus on waste reduction by implementing the 5 R's: reduce, reuse, repair, remanufacture and recycle (Mishra et al. 2019). The reverse flow of products can be induced due to various situations, such as commercial returns, warranty period returns, end-of-use returns, and others (Fleischmann 2001). According to an Allied Market Research report (2019), the total share of the commercial or warranty returns in 2017 was one-third of the total market share and is expected to retain its revenue lead through 2025. However, end-of-life returns are expected to grow rapidly from 2018 to 2025. Thus, a firm that has its own reverse logistics network can recapture valuable materials from returned products (Reddy et al. 2018), which can help the firm build a competitive advantage alongside achieving corporate social responsibility (CSR) targets (Chen et al. 2017). For example, some European tire manufacturers recycle at least one old tire to produce every new tire they sell (Cognizant 2020 Insights 2011). In addition, a Business Strategy Report (2015) reveals the significance of analysing customers' product returns and purchases over time to determine whether customers more likely to increase purchase rates than return rates. The report further highlights that through product return services, firms may be able to build loyalty through continuous interactions regarding returned products and invite more positive word of mouth, which results in repetitive purchases.

According to Erica (2018), the apparel industry is the major contributor to the rising return rate, followed by consumer electronics such as smartphones, laptops, tablets, and others. The rate of return for electronic items ranges from 5 to $15 \%$ and is even higher for some companies. A survey report reveals that $67 \%$ of customers check a firm's return policy before making a purchase. The same survey highlighted that $58 \%$ of customers prefer a hasslefree return policy, and $79 \%$ of customers prefer free return shipping. In view of this, firms need to strengthen their reverse logistics network to create monetary value from product recovery as well as for increased customer satisfaction by establishing their own reverse logistics (RL) network that incorporates remanufacturing and repair facilities (Reddy et al. 2018). However, planning, designing, and managing an RL network is complex and involves numerous processes, such as collection, sorting, segregation, repair, remanufacturing, and safe disposal of the used products (Liao 2018). Therefore, the strategic decisions related to RL configuration include well-calculated tactical and operational decisions.

The aspects mentioned above motivated the design of a dynamic reverse logistics network that focuses on post-sale service dealing with warranty returns. An attempt has been made to include repair and remanufacturing facilities in an internationally operating manufacturing network. Ivanov et al. (2010) highlighted the potential of supply chain management to improve business performance. They asserted that a well-managed supply chain could cause a $15-30 \%$ reduction in the total cost and an increase in sales. Efficiently configured supply chains provide a competitive advantage to firms, as they account for $80 \%$ of the total product 
cost (Ivanov et al. 2009). The complexity of supply chains has increased due to globalization and other macro trends. This shift has brought more sensitivity to adverse events and made it imperative for practitioners to consider disruptions while working in the design and management of supply chains (Aldrighetti et al. 2019). Thus, this paper proposes a mathematical model for the optimal configuration of a global supply chain network and its management that includes reverse logistics. The significant contributions of the paper are summarized as follows:

1. Designing a mathematical model to identify the optimal facility location for forward logistics and remanufacturing and repair centres.

2. Linearizing the MINLP to MILP to reduce the computation time.

3. The proposed mathematical model also explores the possibility of expanding the capacity of existing plants and warehouses to accommodate the returned products when the establishment of new remanufacturing and repair facilities is not profitable.

4. Furthermore, the developed MILP model provides the optimal product flow in the forward and reverse directions.

5. The dynamic hybrid facility network model with flexible plant-warehouse capacity helps to address demand/supply disruption in the supply chain.

The remaining sections of the paper are organized as follows: Sect. 2 provides the literature related to reverse logistics and international manufacturing networks. Section 3 discusses the model parameters and the mathematical formulation. Section 4 describes the application of the proposed mathematical model through a hypothetical dataset, followed by a discussion of the results in Sect. 5. Section 6 outlines the implications of the research, followed by a conclusion in Sect. 7.

\section{Literature review}

The literature review is divided into two subsections. The first section provides a detailed discussion of reverse logistics and the past approaches to incorporate it into mathematical models. The second section discusses past studies related to the international manufacturing network. The SCOPUS database is used to find related studies. The keyword search procedure is followed to thoroughly scrutinize the database regarding the titles, abstracts, and keywords using three combinations: (a) RL/closed-loop supply chain management (CLSCM) and international manufacturing, (b) RL/CLSCM and global manufacturing, and (c) RL/CLSCM and manufacturing. No results were found for the first combination, four results were found for second combinations, and more than 1500 results were obtained for the third combination. It is evident from the search results that international manufacturing has yet to attract much attention from researchers; however, a great deal of research work has been carried out in the manufacturing literature. Figure 1 demonstrates the year wise publications on RL/CLSCM and manufacturing published in leading journals indexed in the SCOPUS database. The analysis of the overall trend reveals that the number of publications in this research domain has witnessed exponential growth, thereby delineating the importance of incorporating reverse logistics in the context of manufacturing. In addition, more than $60 \%$ of these papers have been published in the last ten years, indicating the popularity and potential of the domain for research. 


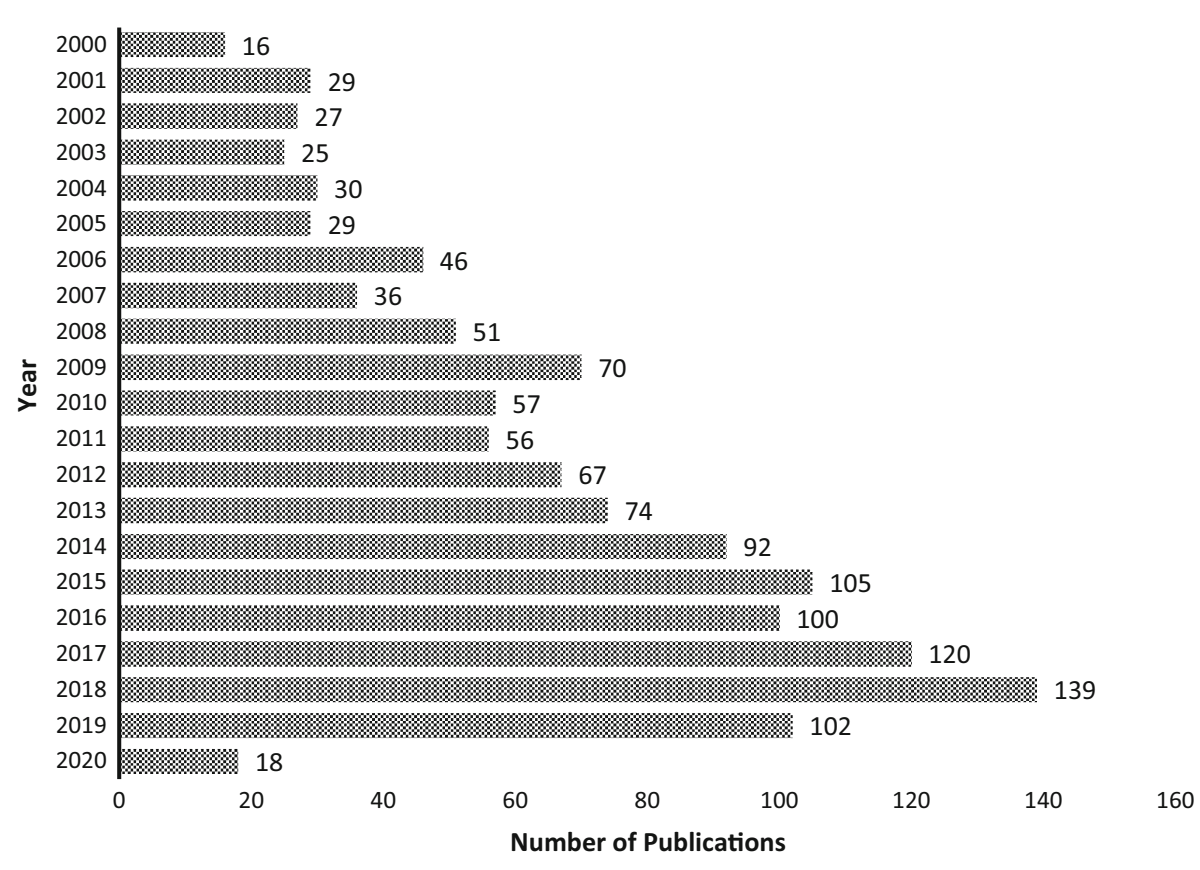

Fig. 1 Year-wise publication on RL/CLSCM from 2000 to March 2020

\subsection{Review of closed-loop supply chains and reverse logistics}

In the past decade, increasing concern over environmental problems has led to the formulation of stringent legislation for product manufacturers and distributors for the proper disposal of products after their useful life. In addition, the huge cost saving opportunity due to product returns has motivated researchers and industrialists to develop more reliable and effective strategies for their reverse logistics. In this direction, Du and Evans (2008) provided a bi-objective mathematical modelling framework for an RL network with the objectives of minimizing total cost and tardiness. They considered third-party logistics (3PL) for product distribution and solved the model using the combination of scatter search, dual simplex, and constraint methods. The outcome for their first objective suggests a centralized network structure, whereas for the second objective, the decentralized network structure is favourable. The seminal work by Min and Ko (2008) provided a MILP formulation for integrating backward logistics into existing forward logistics. They solved the problem using a genetic algorithm (GA). They suggested that location decisions should be altered with the progression of the product's life cycle because the demand for the product varies at each stage. Pishvaee et al. (2009) studied a closed-loop model under uncertainty of quality and quantity of returned products. They developed a stochastic MILP model and employed a scenario-based approach. For cost savings and pollution reduction, they considered hybrid distribution-collection facilities in the model so that material-handling equipment and infrastructure can be shared. The seminal work carried out by Abdallah et al. (2012) developed a closed-loop mathematical model for single plant manufacturing of one type of product under demand uncertainty. Kaya et al. (2014) studied the reverse logistics network under uncertainty in demand and returns. They analysed the behaviour of the system with a two-stage approach using stochastic opti- 
mization and robust optimization. Ivanov et al. (2014) developed an optimal distribution network model for multi-stage, multi-period, and multi-commodity problems. They considered additional warehouses to accommodate returned products that remain unprocessed and non-stored due to the limited capacity of processing and storage facilities. They incorporated the real logic of decision making in industries to transition the model from linear programming to a maximal flow problem. Furthermore, they analysed the model performance for optimistic and pessimistic scenarios. Kannan et al. (2016) developed a mathematical model for a reverse logistics network from the perspective of 3PL. They highlighted the need for increasing consumer awareness regarding product reuse to enhance the cost effectiveness of the reverse logistics network.

In addition to the above social, economic, and environmental concerns, a few researchers have addressed the recycling of end-of-life vehicles (ELVs) due to strict legislation. For instance, Ozceylan et al. (2017) studied the closed-loop supply chain model for the treatment of ELVs. They developed a multi-product, multi-period MILP model with profit maximization as the objective. Gianesello et al. (2017) studied a six-echelon closed-loop supply chain in the context of disaster resilience. They simulated various recovery options and compared their effectiveness in restoring operational performance. John et al. (2017) developed a mathematical model for a multi-period, multi-product reverse logistics network considering the emission cost. They tested the usefulness of the model in a refrigerator recovery supply chain. They further extended this work by incorporating the bill of material of the product in the mathematical model developed above (John et al. 2018). Jerbia et al. (2018) developed a CL model for multiple recovery facilities with uncertainty in return rates, costs, and return quality. Furthermore, they have investigated the impact of changing the input parameters on the overall profit and the network structure. The seminal work by Mishra and Singh (2020b) proposes a stochastic model for a global facility network considering reverse logistics. They have addressed the crucial issues of cross-border trade. Similarly, Liao (2018) proposed a mixed-integer nonlinear model for reverse logistics and solved it using a hybrid GA. Zhen et al. (2019) proposed a two-stage stochastic MINLP model for facility location in a closedloop supply chain and solved it using an improved tabu search approach. In a seminal work, Reddy et al. (2018) used three-phase heuristics to solve the model. They incorporated carbon footprints in their RL model. Furthermore, they compared the results obtained from the heuristic solution approach with the Benders decomposition and Branch and Cut approach. For more details, refer to Mishra and Singh (2019) and Mishra and Singh (2020a).

\subsection{Review of international manufacturing networks for global supply chains}

Researchers have developed various mathematical models to design a production-distribution network for global supply chains. For instance, Cohen and Lee (1988) proposed an integerprogramming model to incorporate international trade issues into a production-distribution network. They estimated the profit of the firm before and after tax for the single-period problem. However, they further extended their model to multiple periods. In seminal work, Kouvelis et al. (2004) proposed an international facility network model to address crossborder trade issues. They have investigated the role of subsidized financing, tariffs, local laws and taxation in shaping the production and distribution network of a firm at the global level. Melo et al. (2006) developed a model to design a dynamic supply chain network and addressed the challenges in supply chain planning. Ivanov et al. (2013) provided a multi-objective production-distribution network model for a centralized upstream network considering structure dynamics. They transformed the traditional linear programming model 
to a maximal flow problem and excluded the demand constraint and focused on an improved service level. Dong et al. (2013) investigated the global production-distribution network in the presence of a competitive environment. In addition, a few researchers have highlighted the importance of collaboration between manufacturers and global logistics service providers, such as Bhatnagar and Viswanathan (2000), who highlighted the issues that have a significant influence on the collaboration of manufacturing firms and third-party logistics services. They further highlighted the trade-offs in such an alliance. Creazza et al. (2010) studied various global logistics network structures and investigated their cost effectiveness using a simulation. For more details on global supply chains, refer to Ivanov et al. (2017).

The literature also reveals that researchers are giving due attention to the integration of critical supply chain issues while developing mathematical models. For instance, Amin and Baki (2017) developed a multi-objective mathematical model for a closed-loop supply chain that simultaneously addresses international trade issues. They solved the model using fuzzy programming, where one objective minimizes the product delivery time from suppliers and the second maximizes the total profit. Srinivasan and Khan (2018) developed a MILP model for manufacturing/remanufacturing facility distribution in an uncertain environment. Ganji et al. (2017) conducted a survey to consult experts from a global tire manufacturing firm to investigate the significance of demand chain and supply chain integration with global firms. They concluded that these integrations are motivated by opportunities for potential financial gains. They highlighted the role of a positive mindset in employing sustainable practices. Hosseini et al. (2019) proposed a mixed-integer model for resilient supply bases for global value chains to address disruptions due to exceptional and operational risks. Their optimization model considers various proactive and reactive approaches, such as supplier segregation, backups, supplier reliability and supplier restoration capability, to address disruptions. Tan et al. (2019) focused on structural analysis for a speedy recovery after a supply chain network disruption. More recently, Ivanov (2020a) carried out a simulation-based analysis on coronavirus outbreaks to predict the impact of epidemic outbreaks on global supply chains. In a seminal work, Ivanov and Dolgui (2020) proposed a conceptual model for the viability of intertwined supply networks. Ivanov (2020b) studied the viable supply chains spanning three crucial supply chain perspectives viz. sustainability, resilience, and agility. Seminal work by Dolgui et al. (2020) proposes a conceptual model for reconfigurable supply chain. They focussed on the integration of resilience, digitalization, sustainability and leagility in a supply chain network. For a detailed perspective on global supply chains, see Mishra and Singh (2020b), Mishra et al. (2019), Ivanov et al. (2017).

The literature survey reveals that a rich body of literature is available on the models related to RL and closed-loop supply chains. However, studies exploring RL in the context of an international manufacturing network are limited. Table 1 summarizes the related literature that has been reviewed and the mathematical models available so far, thus identifying the existing gap in the literature. Furthermore, the possibility of the capacity expansion of existing facilities instead of establishing new facilities to facilitate the reverse flow of products has not been given due attention. Flexibility in capacity helps to hedge against the variability in market demand (Ivanov 2010; Ivanov et al. 2018). This argument is further supported by Shekarian et al. (2020) to examine the impact of flexibility in mitigating disruptions in the supply chain. This significant gap in the existing literature has motivated the development of a comprehensive mathematical model that presents an integrated consideration of these parameters. In view of this, a multi-product, multi-country, and multi-period non-linear mathematical programming (MINLP) model is proposed to design an international production-distribution network that also considers reverse logistics. The proposed model considers the flexible capacities of plant and warehouse facilities to accommodate 
the products returned for repair and remanufacturing services. The reason for this consideration is to enable equipment and infrastructure sharing among the facilities, consequently increasing the firm's cost-saving opportunity. Recognizing the complexity of the international manufacturing-remanufacturing network, the MINLP model is linearized to MILP. The objective of the developed MILP model is to find the optimal network configuration along with minimizing the total cost, including the import-export cost, remanufacturing cost, repair cost and depreciation expense on machinery. The model is validated using various randomly generated datasets and explained using a reasonable amount of data instances.

\subsection{Research gaps}

The thorough analysis of the relevant journal papers, book chapters, conference proceedings and business articles highlighted the following research gaps. The paper addresses these research gaps by proposing a comprehensive mathematical formulation for an international manufacturing network.

- There are few studies on production-distribution network models addressing international trade issues.

- Global supply chain models providing country-wise analysis are not available.

- Limited attention is given to incorporating reverse logistics into the global facility network.

- Models considering hybrid facilities with flexible capacity are not adequately addressed.

Based on the above research gaps, various research questions are derived. The research questions are provided in Sect. 2.3.1, and the research objectives are given in Sect. 2.3.2.

\subsubsection{Research questions}

- How can the optimal configuration for the production-distribution network be designed at the global level?

- Does country-specific analysis support better operations understanding and future decision making?

- How should the firm design a global supply chain network to support the circular economy?

- How should the firm decide between capacity expansion and the establishment of a new facility?

\subsubsection{Research objectives}

- To design a multi-product and multi-period model for a global production-distribution network interlinking production and storage facilities with demand locations in different countries.

- To propose a model for analysing and comparing the country-specific operational performance of the firm.

- To consider hybrid facilities, i.e., forward logistics facilities also provide services for reverse logistics to support the circular economy.

- Consider capacity expansion to provide flexibility and adaptability to hedge against the disruptions in demand and supply.

The above defined research objectives are addressed in the paper by developing a mathematical model. The proposed model provides the operational information of the firm in 


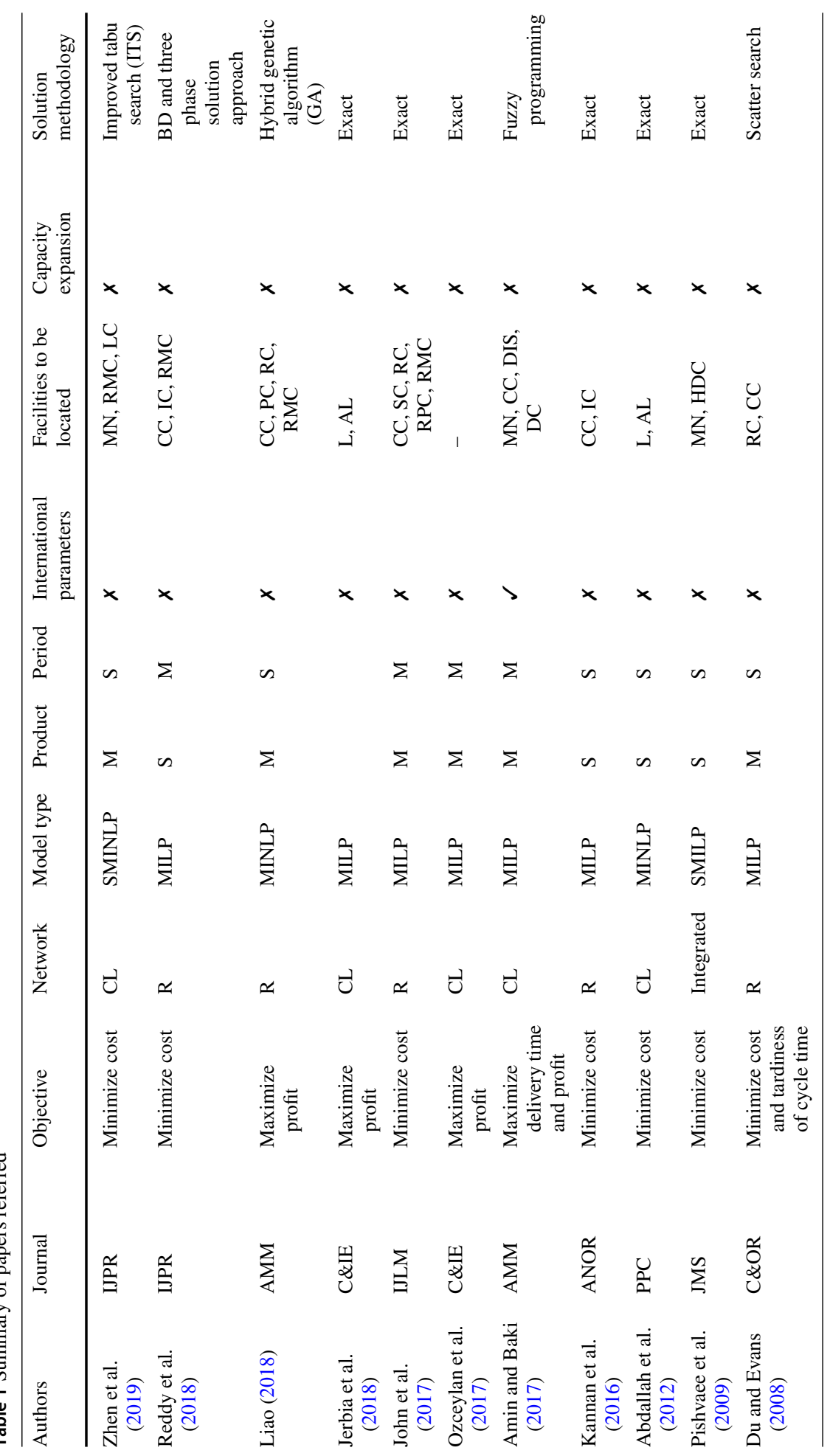




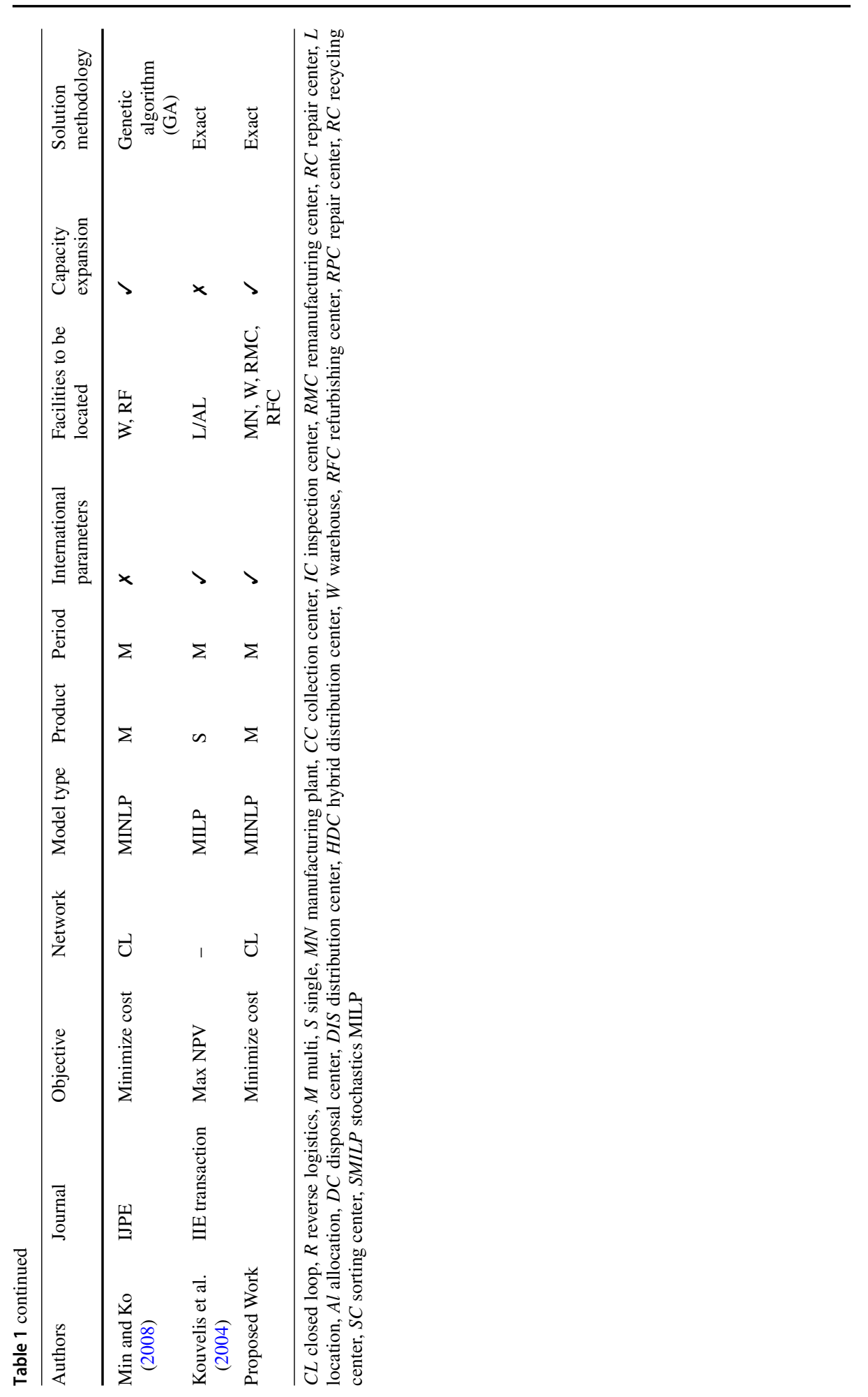


each country separately. This country-specific analysis of a global supply chain network supports comparative and targeted decision making. Reverse logistics is considered in the model because of product returns under the warranty period. A hybrid plant-warehouse network is considered due to its cost saving potential. Furthermore, to address this dual pressure of product returns and forward logistics operations on facilities, capacity expansion is considered. The proposed model is a MINLP model, which is transformed to an MILP using binary equivalents to reduce the computational time.

\section{Mathematical model}

\subsection{Problem statement}

The paper addresses the problem of designing a multi-product, multi-facility, and multi-period network configuration for a global manufacturing firm. To support the circular economy, the firm provides post sale services such as repair and remanufacturing. The model focuses on the product returns under the warranty period. The problem of optimal facility locations is investigated to satisfy the demand from different markets. A hybrid plant-warehouse network is taken into consideration because it provides huge cost-saving opportunity due to space, technology, and equipment sharing, etc. The returned products are collected at warehouses also equipped for collection and repair services where the products are examined for possible repair. However, if the repairing of a product is not possible, it is sent to the plant for remanufacturing. In the proposed model, it is considered that existing plants can also act as remanufacturing centers. Similarly, existing warehouses can also serve as collection/repairing centers. However, if required, new facilities can be established for forward or backward logistics or both. Further, the capacity expansion is taken into consideration to facilitate the reverse flow of the product. The novelty of the model proposed in the paper is in addressing the crucial supply chain issues such as facility network configuration, reverse logistics, capacity flexibility, and production-distribution in a single MILP model. The problem is formulated keeping in view the challenges of today's globalized world, which is highly dynamic and volatile. The decentralized model proposed in the paper is country-specific and effectively deals with the variations in the local needs of the different countries. However, the interconnected facilities within a country and across countries make the model more robust and resilient to disruptions. Furthermore, another novelty of the proposed model is that it focuses on post-sale services such as repair and remanufacturing under warranty returns as saleability of the product reduces if it does not offer any post-sale service. The dynamic MILP model re-considers and re-evaluates various operational decisions such as facility allocation, production-distribution quantities, capacity expansion in each period, thus, making the proposed model more flexible and realistic. Generally, the management of supply chain and its planning requires algorithms and refer operations research methods such as linear programming, integer/mixed-integer programming, stochastic and dynamic programming approaches (Ivanov et al. 2010). Heuristics and meta-heuristics are also applied to solve large and complex problems. They are computationally efficient. However, the solution provided may or may not be optimal. Therefore, the proposed model is solved using the exact approach, which provides an optimal and admissible solution for all the data instances. In this setting, we made the following underlying assumptions:

- Product demand in each market in each country is dynamic and known with certainty.

- The potential facility locations are pre-identified. 
- The plants and warehouses have flexible capacities with known maximum capacity limit.

- The capacity expansion arrangements cover a period within which no significant changes occur in market demand and transportation infrastructure.

- Trade tariffs are estimated per unit of product.

\subsection{Mathematical formulation}

\subsubsection{List of indices}

$b, c=$ index of countries. $b, c \in \mathrm{C}$ (countries are referred as $\mathrm{C} 1, \mathrm{C} 2 . . \mathrm{Cc}$ ).

$i=$ plant (plants are referred as Ii).

$j=$ warehouse (warehouses are referred as $\mathrm{Jj}$ ).

$k=$ market (markets are referred as $\mathrm{Kk}$ ).

$p=$ product (referred as $\mathrm{Pp}$ ).

$t=1,2 \ldots, \mathrm{T}$ time period (referred as $\mathrm{Tt})$.

\subsubsection{List of parameters}

$F 1_{i c t}=$ Fixed maintenance cost of plant $i$ in country $c$ for period $t$.

$F 2_{j c t}=$ Fixed maintenance cost of warehouse $j$ in country $c$ for period $t$.

$F P N_{i c t}=$ Fixed establishment cost of plant $i$ in country $c$ for period $t$.

$F P E_{i c t}=$ Fixed expansion cost of plant $i$ in country $c$ for period $t$.

$V P E_{i c t}=$ Variable expansion cost of plant $i$ in country $c$ for period $t$.

$U A_{i c t}=$ Maximum capacity expansion limit of plant $i$ in country $c$ for period $t$.

$F W N_{j c t}=$ Fixed establishment cost of warehouse $j$ in country $c$ for period $t$.

$F W E_{j c t}=$ Fixed expansion cost of warehouse $j$ in country $c$ for period $t$.

$V W E_{j c t}=$ Variable expansion cost of warehouse $j$ in country $c$ for period $t$.

$U B_{j c t}=$ Maximum capacity expansion limit of warehouse $j$ in country $c$ for period $t$.

$C P_{\text {pict }}=$ Production cost of product $p$ in plant $i$ in country $c$ for period $t$.

$C R_{\text {pict }}=$ Cost of remanufacturing produc $p$ in plant $i$ in country $c$ for period $t$.

$Q P_{\text {pict }}{ }^{\max }=$ Maximum production limit of plant $i$ at country $c$ for product $p$ in period $t$.

$Q W_{p j c t}^{\max }=$ Maximum storage limit of warehouse $j$ located in country $c$ to store product $p$ in period $t$.

$R F_{p j c t}=$ Per unit cost of refurbishing product $p$ at warehouse $j$ located in country $c$ in period $t$.

$T 1_{\text {pici'bt }}=$ Cost of transporting a unit of product $p$ from plant $i$ located in country $c$ to plant $i$ located in country $b$ for period $t$.

$T 2_{\text {picjbt }}=$ Cost of transporting a unit of product $p$ from plant $i$ located in country $c$ to warehouse $j$ located in country $b$ for period $t$.

$T 3_{\text {pickbt }}=$ Cost of transporting a unit of product $p$ from plant $i$ located in country $c$ to market $k$ located in country $b$ for period $t$.

$T 4_{p j c j^{\prime} b t}=$ Cost of transporting a unit of product $p$ from warehouse $j$ located in country $c$ to warehouse $j^{\prime}$ located in country $b$ for period $t$.

$T 5_{p j c k b t}=$ Cost of transporting a unit of product $p$ from warehouse $j$ located in country $c$ to market $k$ located in country $\mathrm{b}$ for period $t$.

$T 7_{p k j c t}=$ Cost of transporting a unit of product $p$ from market $k$ located to warehouse $j$ in country $c$ for period $t$ (to and fro). 
$T 8_{\text {pjcict }}=$ Cost of transporting a unit of product $p$ from warehouse $j$ to plant $i$ located in country $c$ for period $t$ (to and fro).

$Q S_{p k c t}=$ pth product demand at market $k$ in countryc for period $t$.

$H_{p j c t}=$ Holding cost per unit of product $p$ in country $c$ for period $t$.

$T 6_{p c b t}=$ Import/Export cost per unit of product $p$ transported from country $c$ to country $b$ for period $t$.

$D P_{\text {pict }}=$ Depreciation expense per unit of product $p$ in plant $i$ located in country $c$ for period $t$.

$D R_{\text {pict }}=$ Depreciation expense due to remanufacturing per unit of product $p$ in plant $i$ located in country $c$ for period $t$.

$R_{p k c t}=$ quantity of returned products of type $p$ from market $k$ in country $c$ in period $t$.

$Q 6_{\text {pkjct }}=$ quantity of product $p$ returned from market $k$ to warehouse $\mathrm{j}$ in country c for period $t$.

\subsubsection{List of variables}

$$
\begin{aligned}
X_{i c t} & = \begin{cases}1 & \text { if plant } i \text { open in country } c \text { for period } t \\
0 & \text { otherwise }\end{cases} \\
Y_{j c t} & = \begin{cases}1 & \text { if warehouse } j \text { is open in country } c \text { for period } t \\
0 & \text { otherwise }\end{cases} \\
V_{i c t} & =\left\{\begin{array}{ll}
1 & \text { if capacity of plant } i \text { is expanded in country } c \text { for period } t \\
0 & \text { otherwise }
\end{array} .\right. \\
U_{j c t} & =\left\{\begin{array}{ll}
1 & \text { if capacity of warehouse } j \text { is expanded in country } c \text { for period } t \\
0 & \text { otherwise }
\end{array} .\right. \\
Q P_{\text {pict }}=\text { Production at plant } i \text { in country } c \text { for product } p \text { in period } t . &
\end{aligned}
$$

$Q R M_{p k j i c t}=$ Quantity of product $p$ remanufactured at plant $i$ returned from market $k$ via warehouse $j$ in country $c$ for period $t$.

$Q R F_{p k j c t}=$ Quantity of product $p$ refurbished at warehouse $j$ returned from market $k$ located in country $c$ in period $t$.

$I N_{p j c t}=$ Balance inventory of product $p$ at warehouse $\mathrm{j}$ located in country $c$ for period $t$.

$Q 1_{\text {pici'bt }}=$ unit of product $p$ shipped from plant $i$ located in country $c$ to plant $i^{\prime}$ in country $b$ for period $t$.

$Q 2_{\text {picjbt }}=$ unit of product $p$ shipped from plant $i$ in country $c$ to warehouse $j$ in country $b$ for period $t$.

$Q 3_{\text {pickbt }}=$ unit of product $p$ shipped from plant $i$ in country $c$ to market $k$ in country $b$ for period $t$.

$Q^{4}{ }_{p j c j^{\prime} b t}=$ unit of product $p$ shipped from warehouse $j$ located in country $c$ to warehouse $j$ located in country $c$ for period $t$.

$Q 5_{p j c k b t}=$ unit of product $p$ shipped from warehouse $j$ in country $c$ to market $k$ in country $b$ for period $t$.

$K 2_{i c t}=$ Total expanded capacity of plant $i$ in country $c$ in period $t$.

$K 1_{j c t}=$ Total expanded capacity of warehouse $j$ in country $c$ in period $t$.

\subsubsection{MINLP model formulation}

\section{- Objective function}

The various fixed and variable costs denoted from (a) to (h) summed up to form the objective function of the proposed MINLP. The costs are as follows: 
(a) Fixed cost

$$
\begin{aligned}
F C_{c t}= & \sum_{i} F 1_{i c t} X_{i c t}+\sum_{i} F P N_{i c t} X_{i c t}\left(1-X_{i c t-1}\right)+\sum_{i} F P E_{i c t} V_{i c t} \\
& +\sum_{i} V P E_{i c t} K 2_{i c t}+\sum_{j} F 2_{j c t} Y_{j c t}+\sum_{j} F W N_{j c t} Y_{j c t}\left(1-Y_{j c t-1}\right) \\
& +\sum_{j} F W E_{j c t} U_{j c t}+\sum_{j} V W E_{j c t} K 1_{j c t} \forall c, t
\end{aligned}
$$

The first and the fifth term of Eq. (1) corresponds to the cost of maintaining the existing plants and warehouses. Second term and sixth term represent the cost of establishing new plants and warehouses which were not existing/operating in previous time period. Third and seventh term represent the fixed cost of expansion of plant and warehouse. Fourth term and last term represent the variable cost of capacity expansion. The production cost and the remanufacturing cost per unit of product are given in Eqs. (2) and (3).

(b) Production cost

$$
P C_{c t}=\sum_{p} \sum_{i} Q P_{p i c t} C P_{p i c t} \quad \forall c, t
$$

(c) Remanufacturing cost

$$
R M C_{c t}=\sum_{p} \sum_{i} \sum_{j} \sum_{k} Q R M_{p k j i c t} C R_{p i c t} \forall c, t
$$

(d) Inventory carrying cost

$$
I H_{c t}=\sum_{p} \sum_{j} H_{p j c t} I N_{p j c t} \quad \forall c, t
$$

Equation (4) provides the inventory carrying cost for holding the leftover product at warehouse. The inventory carrying cost is taken into consideration for only forward logistics. However, for reverse product flow, it is assumed that returned items are repaired or directly shipped to plant as soon as they are received; therefore, the holding cost for reverse logistics is neglected.

(e) Transportation cost

$$
\begin{aligned}
T C_{c t}= & \sum_{\mathrm{p}} \sum_{\mathrm{i}} \sum_{\mathrm{i}} \sum_{b} T 1_{\text {pici'bt }} Q 1_{\text {pici'bt }}+\sum_{\mathrm{p}} \sum_{\mathrm{i}} \sum_{\mathrm{j}} \sum_{b} T 2_{p i c j b t} Q 2_{p i c j b t} \\
& +\sum_{\mathrm{p}} \sum_{\mathrm{i}} \sum_{\mathrm{k}} \sum_{b} T 3_{\text {pickbt }} Q 3_{\text {pickbt }} \sum_{\mathrm{p}} \sum_{\mathrm{j}} \sum_{\mathrm{j} \mathrm{j}^{\prime}} \sum_{b} T 4_{p j c j^{\prime} b t} Q 4_{p j c j^{\prime} b t} \\
& +\sum_{\mathrm{p}} \sum_{\mathrm{j}} \sum_{k} \sum_{b} T 5_{p j c k b t} Q 5_{p j c k b t}+\sum_{\mathrm{p}} \sum_{\mathrm{j}} \sum_{\mathrm{k}} \sum_{i} T 8_{p j c i c t} Q R M_{p k j i c t} \\
& +\sum_{\mathrm{p}} \sum_{\mathrm{j}} \sum_{k} T 7_{p k c j c t} Q R F_{p k j c t} \quad \forall c, t
\end{aligned}
$$

Equation (5) provides the shipment cost from plants to other facilities or to markets. The first term represents the cost of shipping from plants to plants, second term represents from plant to the warehouse, then, plant to market by third term, warehouse to warehouse by fourth term and warehouse to market by fifth term. Similarly, sixth 
term provides the cost of transporting the products for remanufacturing from warehouse to plant. These costs include both side movements from warehouse to plant as well as from plant to customerlwarehouse. Similarly, the last term represents the transportation cost linked to product return at warehouse.

(f) Import/export duties

$$
\begin{aligned}
I E_{c t}= & \sum_{p} \sum_{i} \sum_{i^{\prime}} \sum_{b} T 6_{p c b t} Q 1_{p i c i^{\prime} b t}+\sum_{p} \sum_{i} \sum_{j} \sum_{b} T 6_{p c b t} Q 2_{p i c j b t} \\
& +\sum_{p} \sum_{i} \sum_{k} \sum_{b} T 6_{p c b t} Q 3_{p i c k b t}+\sum_{p} \sum_{j} \sum_{j^{\prime}} \sum_{b} T 6_{p c b t} Q 4_{p j c j^{\prime} b t} \\
& +\sum_{p} \sum_{j} \sum_{k} \sum_{b} T 6_{p c b t} Q 5_{p j c k b t} \forall c, t
\end{aligned}
$$

Equation (6) represents the tariffs imposed for shipping the products to different country. It is taken for the forward logistics only as no inter country movement is considered for reverse logistics.

(g) Depreciation expense

$$
D E_{c t}=\sum_{p} \sum_{i} D P_{p i c t} Q P_{p i c t}+\sum_{p} \sum_{i} \sum_{j} \sum_{k} D R_{p i c t} Q R M_{p k j i c t} \forall c, t
$$

Equation (7) provides the depreciation expense for using the plants machinery for manufacturing/remanufacturing. It is calculated per unit of production. The first term represent the depreciation expense due to manufacturing, and the second term represents the depreciation expense due to remanufacturing.

(h) Repairing cost

$$
R C_{c t}=\sum_{p} \sum_{j} \sum_{k} R F_{p j c t} Q R F_{p k j c t} \quad \forall c, t
$$

Equation (8) represents the cost associated with the refurbishing or repairing the products at warehouse.

$$
\begin{gathered}
\text { TOTAL COST }\left(O C_{c t}\right)=F C_{c t}+P C_{c t}+I H_{c t}+T C_{c t}+I E_{c t} \\
+D E_{c t}+R C_{c t}+R M C_{c t} \quad \forall c, t \\
\operatorname{Minz}=\sum_{c=1}^{C} \sum_{t=1}^{T}\left(O C_{c t}\right)
\end{gathered}
$$

Equation (9) sums up all equations (a) to (h) and Eq. (10) provides the objective function that minimizes the total cost obtained in (9) for all the countries and all the time periods.

- Set of constraints

$$
\begin{gathered}
\sum_{k} R_{p k c t}=\sum_{k} \sum_{j} Q R F_{p k j c t}+\sum_{j} \sum_{i} \sum_{k} Q R M_{p k j i c t} \forall p, c, t \\
R_{p k c t}=\sum_{j} Q 6_{p k j c t} \forall p, k, c, t \\
Q 6_{p k j c t}=Q R F_{p k j c t}+\sum_{i} Q R M_{p k j i c t} \forall p, k, j, c, t
\end{gathered}
$$


Equation (11) ensures that all the products that are returned under warranty period from the markets should be repaired or remanufactured. Equation (12) ensures that all the products returned from a market have been distributed to the warehouses for possible repair or remanufacturing services. Equation (13) ensures that the products returned from Kth market are repaired or refurbished/repaired.

$$
\begin{aligned}
& Q P_{p i c t}+\sum_{j} \sum_{k} Q R M_{p k j i c t}-N M 1_{i c t} M \leq Q P_{p i c t}^{\text {max }} X_{i c t}+\sum_{m=1}^{t} K 2_{i c m} \quad \forall p, i, c, t \\
& Q P_{p i c t}+\sum_{j} \sum_{k} Q R M_{p k j i c t}-\left(1-N M 1_{i c t}\right) M \leq Q P_{p i c t}^{\max } X_{i c t} \quad \forall p, i, c, t \\
& K 2_{i c t} \leq U B_{i c} V_{i c t} \quad \forall i, c, t \\
& \sum_{i} \sum_{b} Q 2_{p i b j c t}+\sum_{j^{\prime}} \sum_{b} Q 4_{p j^{\prime} b j c t}+\sum_{j^{\prime}} \sum_{b} Q 4_{p j^{\prime} b j c t}+\sum_{k} Q R F_{p k j c t}-N M 2_{i c t} M \\
& j^{\prime} \neq j \quad b=c \quad j^{\prime} \neq j \quad b=c \\
& \leq Q W_{p j c t}^{\text {max }} Y_{j c t}+\sum_{m=1}^{t} K 1_{j c m} \quad \forall p, j, c, \\
& \sum_{i} \sum_{b} Q 2_{p i b j c t}+\sum_{j^{\prime}} \sum_{b} Q 4_{p j^{\prime} b j c t}+\sum_{j^{\prime}} \sum_{b} Q^{4 j^{\prime} b j c t}+\sum_{k} Q R F_{p k j c t}-\left(1-N M 2_{i c t}\right) M \\
& j^{\prime} \neq j \quad b=c \quad j^{\prime} \neq j \quad b=c \\
& \leq Q W_{p j c t}^{\max } Y_{j c t}+\sum_{m=1}^{t} K 1_{j c m} \quad \forall p, j, c, \\
& K 1_{j c t} \leq U B_{j c} U_{j c t} \quad \forall i, c, t
\end{aligned}
$$

Equations (14a) and (14b) balance the production and remanufacturing quantities at plants and ensure that it do not exceed the plant capacity. Equation (15) put a limitation on the expansion capacity of plant. Similarly, Eqs. (16) and (17) ensures that the capacity of the warehouse is not exceeded and provide an upper limit for expansion.

$$
\begin{aligned}
& (\mathrm{T}-\mathrm{t}+1) V_{i c t} \leq \sum_{m=t}^{T} X_{i c m} \quad \forall i, c, t \\
& (\mathrm{~T}-\mathrm{t}+1) U_{j c t} \leq \sum_{m=t}^{T} Y_{j c m} \quad \forall j, c, t
\end{aligned}
$$

Equations (18) and (19) ensures that the plants and warehouse that are expanded should operate in subsequent time periods.

$$
\begin{gathered}
Q S_{p k c t}=\sum_{i} \sum_{b} Q 3_{\text {pibkct }}+\sum_{j} \sum_{b} Q 5_{\text {pjbkct }} \forall c, t, k, p \\
Q P_{\text {pict }}+\sum_{\substack{i^{\prime} \\
i^{\prime} \neq i \quad b=c}} \sum_{b} Q 1_{p i^{\prime} b i c t}+\sum_{i^{\prime}} \sum_{\substack{b \\
b \neq c}} Q 1_{\text {pi'bict }}
\end{gathered}
$$




$$
\begin{aligned}
= & \sum_{\substack{i^{\prime \prime} \\
i^{\prime \prime} \neq i \quad b=c}} \sum_{b} Q 1_{p i c i^{\prime \prime} b t}+\sum_{i^{\prime \prime}} \sum_{b} Q 1_{p i c i^{\prime \prime} b t} \\
& +\sum_{j} \sum_{b} Q 2_{p i c j b t}+\sum_{k} \sum_{b} Q 3_{\text {pickbt }} \quad \forall c, t, i, p
\end{aligned}
$$

Equation (20) balances the product flow. Equation (21) balances the product flow at plants.

$$
\begin{aligned}
& \sum_{i} \sum_{b} Q 2_{p i b j c t}+\sum_{\substack{j^{\prime} \\
j^{\prime} \neq j}} \sum_{b=c} Q 4_{p j^{\prime} b j c t}+\sum_{j^{\prime}} \sum_{\substack{b \\
b \neq c}} Q 4_{p j^{\prime} b j c t}+I N_{p j c(t-1)} \\
& =\sum_{k} \sum_{b} Q 5_{p j c k b t}+\sum_{\substack{j^{\prime} \\
j^{\prime} \neq j \quad b=c}} \sum{ }^{4}{ }_{p j c j^{\prime} b t} \\
& +\sum_{j^{\prime}} \sum_{b} Q 4_{p j c j^{\prime} b t}+I N_{p j c t} \forall j, c, t, p \\
& b \neq c
\end{aligned}
$$

Equation (22) provides the inventory balance equation for forward product flow at warehouse.

$$
\begin{gathered}
X_{i c t}, Y_{j c t}, V_{i c t}, U_{j c t}, N M 1_{i c t}, N M 1_{i c t}=0,1 \forall i, j, c, t \\
Q 1_{p i c j b t}, Q 2_{p j c k b t}, Q 5_{p j c j^{\prime} b t}, Q 3_{\text {pickbt }}, Q 4_{\text {pici'bt }}, I N_{p j c t}, \text { are integers } \\
Q R F, Q R M, Q 6 \text { are integers, } M-\text { big number }
\end{gathered}
$$

(23), (24), (25) represent the integer and binary conditions on the decision variables.

\section{- MINLP to MILP transformation}

The model discussed above is non-linear, therefore, to reduce the complexity and computational time, the MINLP is linearized to MILP. The non-linear components of (1) are linearizes below:

- Linearization of $\sum_{i} F P N_{i c t} X_{i c t}\left(1-X_{i c t-1}\right)$

Take a binary variable $Z 1_{\text {ict }}$ such that following conditions hold true:

$$
\begin{gathered}
Z 1_{i c t} \leq X_{i c t} \\
Z 1_{i c t} \leq\left(1-X_{i c t-1}\right) \\
Z 1_{i c t} \geq X_{i c t}+\left(1-X_{i c t-1}\right)-1
\end{gathered}
$$

Equations (26) to (28) ensures that $Z 1_{i c t}=1$ when $X_{i c t}=1$ and $X_{i c t-1}=0$. This implies that if the second term of Eq. (1) is replaced with $\sum_{i} F P N_{i c t} Z 1_{i c t}$ with constraints (26) to (28), then, the cost of a new plant will be included if the plant is not operating in previous period.

- Linearization of $\sum_{j} F W N_{i c t} Y_{j c t}\left(1-Y_{j c t-1}\right)$

Taking a binary variable $Z 2_{j c t}$. such that the following conditions hold true:

$$
Z 2_{j c t} \leq Y_{j c t} .
$$




$$
\begin{gathered}
Z 2_{j c t} \leq\left(1-Y_{j c t-1}\right) . \\
Z 2_{j c t} \geq X_{i c t}+\left(1-Y_{j c t-1}\right)-1 .
\end{gathered}
$$

Similarly, Eqs. (29) to (31) ensures that $Z 2_{j c t} .=1$ when $Y_{j c t} .=1$ and $Y_{j c t-1} .=0$. This implies that if the sixth term of Eq. (1) is replaced with constraints (29) to (31), then, the cost of new plant setup will be included if the warehouse is not operating in previous period. The MILP model is obtained after incorporating these replacements which is solved and discussed in the following section.

\section{Numerical illustration}

The MILP model is tested using different randomly generated datasets of different sizes, and the details are provided in Table 2. The software used to solve the proposed model is Lingo 10 (the code is given in the "Appendix"). The application of the model is explained through a case of two countries and is discussed in detail in 4.1. The first column of Table 2 represents the percentage of a given product $\mathrm{P}$ returned from a given market $\mathrm{K}$ for remanufacturing.

\subsection{Illustration of $2 \mathrm{C}-2 \mathrm{P}-2 \mathrm{I}-3 \mathrm{~J}-2 \mathrm{~K}-3 \mathrm{~T}(\mathrm{QRM}=10 \% \mathrm{Q6})$}

The proposed model is explained with a dataset of two countries $(2 \mathrm{C}$ indicates $\mathrm{c}=2$, i.e., countries denoted as $\mathrm{C} 1$ and $\mathrm{C} 2$ ). The firm wants to find the optimal configuration of facilities to produce two different products ( $2 \mathrm{P}$ indicates $\mathrm{p}=2$, i.e., $\mathrm{P} 1$ and $\mathrm{P} 2$ are the two products). The firm has already identified the predefined set of locations for plants (2I indicates $\mathrm{i}=2$, i.e., $\mathrm{I} 1$ and $\mathrm{I} 2$ are the two plants) and warehouses (3J indicates $\mathrm{j}=3$, i.e., $\mathrm{J} 1$, J2 and $\mathrm{J} 3$ are the three warehouses) in each country to satisfy the product demand from the market zones ( $2 \mathrm{~K}$ indicates $\mathrm{k}=2$, i.e., $\mathrm{K} 1$ and $\mathrm{K} 2$ are the two markets) for each time period (3T indicates $\mathrm{t}=3$, i.e., $\mathrm{T} 1, \mathrm{~T} 2$ and $\mathrm{T} 3$ ). The randomly generated data for this instance are provided in a supplementary file. The existing capacity of all the plants and warehouses for each type of product is 2000 and 2000, respectively. A facility's capacity can be expanded by up to $30 \%$ of the existing capacity in each time period. However, if the capacity of a facility is expanded, then it will operate in all the following periods. The holding cost per unit product per unit time is 0.2. However, the holding cost is not taken into consideration for reverse logistics because the products are repaired and returned as soon as they are received. If repair is not possible, products are quickly moved to the plant for the next course of action. The optimal solution for the considered case is provided in the first row of Table 2. In this case, the quantity of product $p$ remanufactured at all the plants received via warehouse $j$ in country $c$ is taken as $10 \%$ of the total quantity returned from all the markets to warehouse $j$ in that country. Table 3 provides the optimal production and distribution quantities for the considered dataset.

\section{Discussion}

The proposed mathematical model is illustrated using a $2 \mathrm{C}-2 \mathrm{P}-2 \mathrm{I}-3 \mathrm{~J}-2 \mathrm{~K}-3 \mathrm{~T}$ case. The detailed results are provided in Table 3. Forward and reverse flow of product P1and P2 for time period $\mathrm{T} 1$ is provided in Fig. 2. The total demand of product $\mathrm{P} 1$ at all market locations in $\mathrm{T} 1$ in both the countries is 1350 , and for product $\mathrm{P} 2$, the demand is 1300 . The results for 
Table 2 Results for case instances

\begin{tabular}{|c|c|c|c|c|}
\hline $\mathrm{QRM}=\% \mathrm{Q} 6$ & CPU time (LP) & Variables & Constraints & Objective value \\
\hline \multicolumn{5}{|c|}{$2 \mathrm{C}-2 \mathrm{P}-2 \mathrm{I}-3 \mathrm{~J}-3 \mathrm{~K}-3 \mathrm{~T}$} \\
\hline $10 \%$ & 00:01:41 & 1732 & 703 & $3.77238 \mathrm{e}+007$ \\
\hline $20 \%$ & 00:00:27 & 1732 & 703 & $3.77732 \mathrm{e}+007$ \\
\hline $30 \%$ & 00:00:20 & 1732 & 703 & $3.78375 e+007$ \\
\hline $40 \%$ & 00:00:31 & 1732 & 703 & $3.78851 \mathrm{e}+007$ \\
\hline $50 \%$ & 00:01:10 & 1732 & 703 & $3.79463 e+007$ \\
\hline $60 \%$ & 00:00:31 & 1732 & 703 & $3.79967 e+007$ \\
\hline $70 \%$ & 00:00:53 & 1732 & 703 & $3.80611 \mathrm{e}+007$ \\
\hline $80 \%$ & 00:00:07 & 1732 & 703 & $3.81134 \mathrm{e}+007$ \\
\hline $90 \%$ & 00:01:40 & 1732 & 703 & $3.81761 \mathrm{e}+007$ \\
\hline \multicolumn{5}{|c|}{$3 \mathrm{C}-3 \mathrm{P}-3 \mathrm{I}-5 \mathrm{~J}-7 \mathrm{~K}-3 \mathrm{~T}$} \\
\hline $10 \%$ & 00:02:28 & 31,469 & 8425 & $6.71884 \mathrm{e}+008$ \\
\hline $20 \%$ & 00:07:51 & 31,469 & 8425 & $6.72532 e+008$ \\
\hline $30 \%$ & $03: 32: 57$ & 31,469 & 8425 & $6.73103 e+008$ \\
\hline $40 \%$ & $00: 15: 11$ & 31,469 & 8425 & $6.73750 \mathrm{e}+008$ \\
\hline $50 \%$ & $00: 02: 26$ & 31,469 & 8425 & $6.74335 e+008$ \\
\hline $60 \%$ & 28:09:43 & 31,469 & 8425 & $6.75027 e+008$ \\
\hline $70 \%$ & $82: 45: 14$ & 31,469 & 8425 & $* * *$ \\
\hline $80 \%$ & 00:03:00 & 31,469 & 8425 & $6.76261 e+008$ \\
\hline $90 \%$ & 00:04:35 & 31,469 & 8425 & $6.76996 \mathrm{e}+008$ \\
\hline \multicolumn{5}{|c|}{$4 \mathrm{C}-5 \mathrm{P}-3 \mathrm{I}-5 \mathrm{~J}-7 \mathrm{~K}-3 \mathrm{~T}$} \\
\hline $10 \%$ & 00:01:23 & 48,245 & 11,233 & $4.98187 e+008$ \\
\hline $20 \%$ & $00: 32: 48$ & 48,245 & 11,233 & $4.98681 \mathrm{e}+008$ \\
\hline $30 \%$ & $02: 15: 35$ & 48,245 & 11,233 & $4.99155 \mathrm{e}+008$ \\
\hline $40 \%$ & 00:09:18 & 48,245 & 11,233 & $4.99548 \mathrm{e}+008$ \\
\hline $50 \%$ & 00:04:09 & 48,245 & 11,233 & $4.99835 \mathrm{e}+008$ \\
\hline $60 \%$ & 03:09:33 & 48,245 & 11,233 & $5.00445 \mathrm{e}+008$ \\
\hline $70 \%$ & $17 \mathrm{~h}$ & 48,245 & 11,233 & $* * *$ \\
\hline $80 \%$ & $00: 25: 47$ & 48,245 & 11,233 & $5.01162 \mathrm{e}+008$ \\
\hline $90 \%$ & 00:07:15 & 48,245 & 11,233 & $5.01553 e+008$ \\
\hline \multicolumn{5}{|c|}{$5 \mathrm{C}-3 \mathrm{P}-3 \mathrm{I}-5 \mathrm{~J}-7 \mathrm{~K}-3 \mathrm{~T}$} \\
\hline $10 \%$ & $47: 38: 14$ & 41,377 & 8671 & $3.70383 e+007$ \\
\hline $20 \%$ & $00: 06: 23$ & 41,377 & 8671 & $3.71541 \mathrm{e}+008$ \\
\hline $30 \%$ & $04: 05: 24$ & 41,377 & 8671 & $3.72116 e+008$ \\
\hline $40 \%$ & $03: 57: 34$ & 41,377 & 8671 & $3.72248 \mathrm{e}+008$ \\
\hline $50 \%$ & $02: 05: 13$ & 41,377 & 8671 & $3.73611 \mathrm{e}+008$ \\
\hline $60 \%$ & $166: 57: 12$ & 41,377 & 8671 & $3.72788 \mathrm{e}+008$ \\
\hline $70 \%$ & $85: 25: 00$ & 41,377 & 8671 & $* * *$ \\
\hline $80 \%$ & 00:55:06 & 41,377 & 8671 & $3.72461 \mathrm{e}+008$ \\
\hline $90 \%$ & $71: 55: 09$ & 41,377 & 8671 & $3.75984 \mathrm{e}+008$ \\
\hline \multicolumn{5}{|c|}{$5 \mathrm{C}-5 \mathrm{P}-3 \mathrm{I}-5 \mathrm{~J}-7 \mathrm{~K}-3 \mathrm{~T}$} \\
\hline $10 \%$ & $00: 16: 36$ & 68,171 & 14,041 & $6.21538 \mathrm{e}+008$ \\
\hline $20 \%$ & $04: 36: 26$ & 68,171 & 14,041 & $6.22221 \mathrm{e}+008$ \\
\hline $30 \%$ & $02: 35: 46$ & 68,171 & 14,041 & $6.22622 \mathrm{e}+008$ \\
\hline
\end{tabular}


Table 2 continued

\begin{tabular}{lllll}
\hline QRM $=\%$ Q6 & CPU time $(\mathrm{LP})$ & Variables & Constraints & Objective value \\
\hline $40 \%$ & $00: 36: 41$ & 68,171 & 14,041 & $6.23201 \mathrm{e}+008$ \\
$50 \%$ & $00: 08: 36$ & 68,171 & 14,041 & $6.23602 \mathrm{e}+008$ \\
$60 \%$ & $50: 08: 12$ & 68,171 & 14,041 & $* * *$ \\
$70 \%$ & $112: 10: 05$ & 68,171 & 14,041 & $* * *$ \\
$80 \%$ & $06: 36: 06$ & 68,171 & 14,041 & $6.2323 \mathrm{e}+008$ \\
$90 \%$ & $00: 19: 31$ & 68,171 & 14,041 & $6.25825 \mathrm{e}+008$
\end{tabular}

***Solver interrupted manually

the proposed instance suggest to operate plant $\mathrm{I} 1$ in country $\mathrm{C} 1$ for manufacturing product $\mathrm{P} 1$ and plant $\mathrm{I} 1$ in country $\mathrm{C} 2$ for manufacturing product $\mathrm{P} 2$. The plant (I1, C1) produces 1555 units of product $\mathrm{P} 1$ and ships 504 units to $(\mathrm{J} 2, \mathrm{C} 2)$ to meet the demand of $(\mathrm{K} 1, \mathrm{C} 2)=$ 300. In the warehouse (J2, C2), the remaining 204 units of product P1 are stored as inventory. Plant (I1, C1) ships 851 units of P1 to (J3, C1) to satisfy the demand of $(\mathrm{K} 2, \mathrm{C} 1)=400$ and the remaining 451 units are shipped to the warehouse $(\mathrm{J} 1, \mathrm{C} 2)$ to meet the demand of $(\mathrm{K} 2$, $\mathrm{C} 2$ ) and 1 unit is kept as an inventory. However, to satisfy the market demand of (K1, C1) $=200$, plant (I1, C1) ships 200 units of P1 directly to the market. Similarly, forward flow of product P2 can be referred from Fig. 2 depicted using solid red lines. (I1, C2) produces 1300 units of $\mathrm{P} 2$ out of which 600 units are shipped to warehouses $(\mathrm{J} 1, \mathrm{C} 1)=300$ and $(\mathrm{J} 3, \mathrm{C} 1)=300$ to satisfy the demands of markets $(\mathrm{K} 1, \mathrm{C} 1)$ and $(\mathrm{K} 2, \mathrm{C} 1)$ respectively. The reverse flow of the product is depicted using dotted lines. For instance, in country $\mathrm{C} 1,15$ units of product $\mathrm{P} 2$ are returned from market $\mathrm{K} 1$ to warehouse $\mathrm{J} 3$, out of which 13 units are repaired at warehouse $\mathrm{J} 3$ denoted by $13 / 15$, and the remaining 2 units are moved to plant $\mathrm{I} 1$ for remanufacturing denoted by $2 / 15$ in Fig. 2. From Fig. 2, it can be observed that product $\mathrm{P} 2$ is not manufactured in country $\mathrm{C} 1$. However, it is repaired and remanufactured in country $\mathrm{C} 1$. This is because the proposed model assumes that the reverse flow of the product will take place within the country where the market is located even if the product is being manufactured and transported from another country. This assumption is taken into consideration to avoid the transportation cost of shipping a few units of product, which may be much higher than the cost of remanufacturing and repairing at the country of market location. Similarly, 6 units of product $\mathrm{P} 2$ are returned from the market $(\mathrm{K} 2, \mathrm{C} 1)$, out of which 5 are repaired at the warehouse $(\mathrm{J} 3, \mathrm{C} 1)$ denoted by $5 / 6$, and 1 unit is shipped to plant $(\mathrm{I} 1, \mathrm{C} 1)$ for remanufacturing indicated by $1 / 6$. The reverse flow of product P1 is shown using black dotted lines in Fig. 2. For instance, market $(\mathrm{K} 1, \mathrm{C} 1)$ returns 10 units of product P1 to warehouse $(\mathrm{J} 1, \mathrm{C} 1)$ where 9 units are repaired at the warehouse itself denoted by $9 / 10$, and the remaining 1 unit is shipped to plant $(\mathrm{I} 1, \mathrm{C} 1)$ for remanufacturing indicated by $1 / 10$.

For $2 \mathrm{C}-2 \mathrm{P}-2 \mathrm{I}-3 \mathrm{~J}-2 \mathrm{~K}-3 \mathrm{~T}$ case, the results indicate that there is no requirement of an expansion of any plant or warehouse. From Fig. 2, it is clear that the facilities operating in T1 are hybrid and provide both forward and reverse logistics services and no need to set up a new facility for reverse logistics. This is because the existing capacity of the plant and warehouse is sufficient enough to deal with the forward and reverse flow of each product type for the current demand. However, if the existing capacity of the manufacturing plant is reduced from 2000 to 500 for each product type, plants I1 and I3 need to be expanded in the time period T2 and T3, respectively (refer shaded value in Table 4). This expansion will contribute to the expansion cost and increases total cost. Similar experiments are conducted 
Table 3 Detailed solution for $2 \mathrm{C}-2 \mathrm{P}-2 \mathrm{I}-3 \mathrm{~J}-2 \mathrm{~K}-3 \mathrm{~T}$

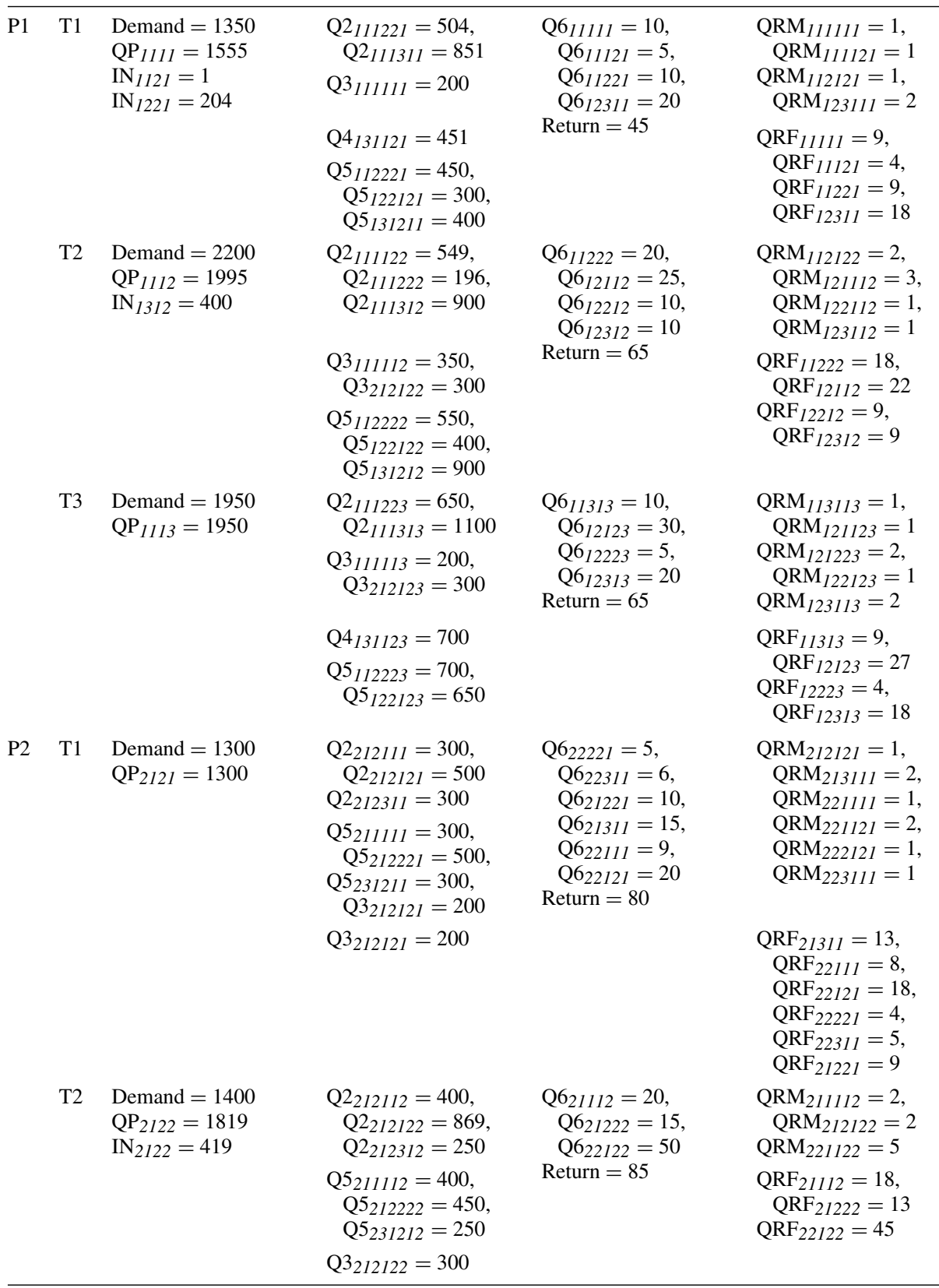


Table 3 continued

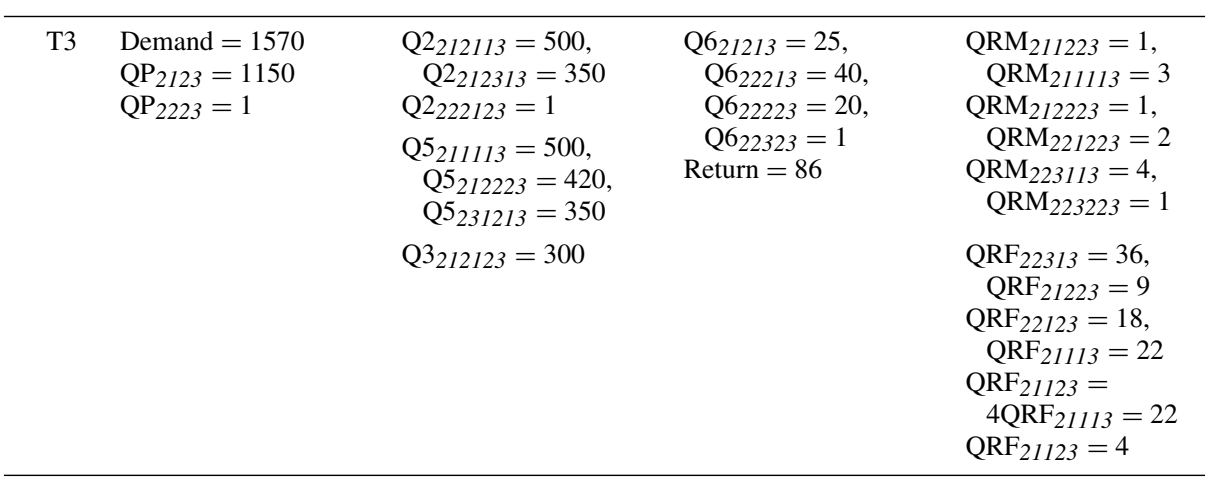

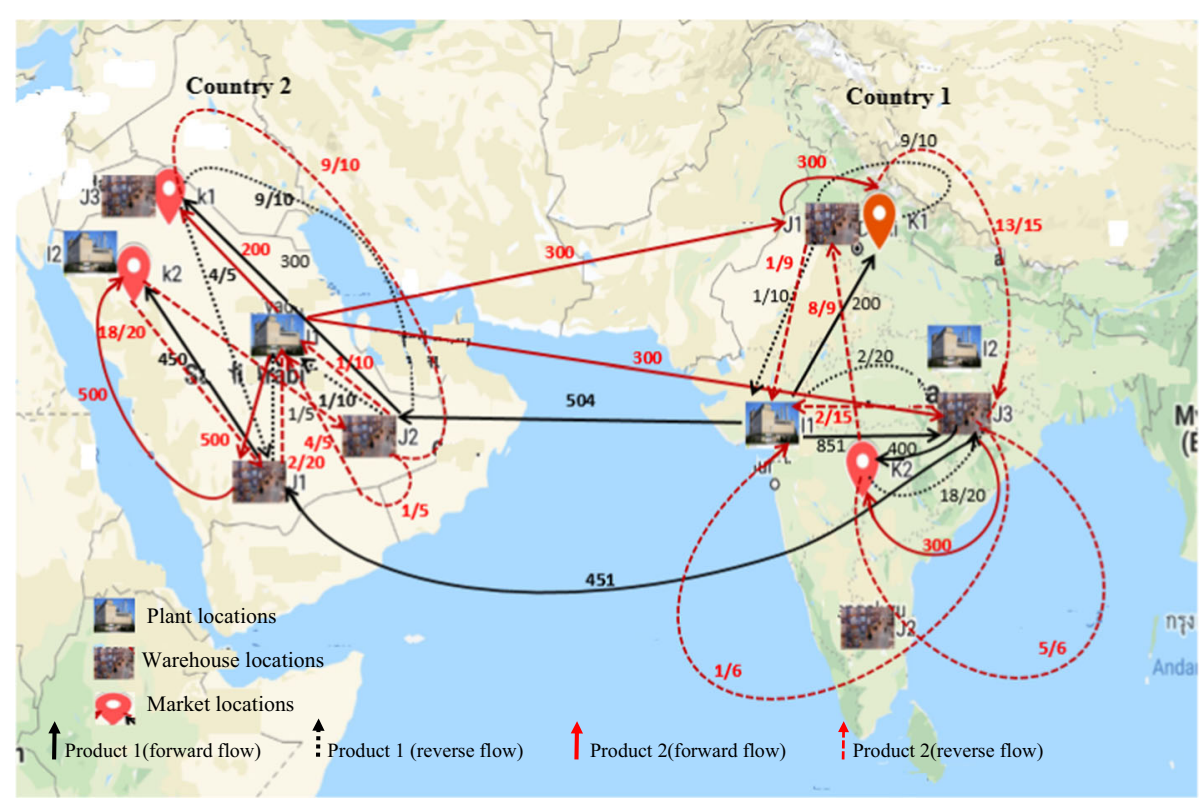

Fig. 2 Forward and reverse logistics distribution network for $2 \mathrm{C}-2 \mathrm{P}-2 \mathrm{I}-3 \mathrm{~J}-2 \mathrm{~K}-3 \mathrm{~T}$

to analyze the effect of changing plant and warehouse capacity on the total cost. The results are provided in Table 4 as follows:

In Table 4, the initial capacity of plants and warehouses for each case is given the first column and corresponding to it, the status of all the active plants and warehouses in country 1 and 2 is provided. For instance, when the initial capacity is $(3000,3000)$, plant I1 (operating in time period 1, 2 and 3) and warehouses J1 (operating in time period 3), J2 (operating in time period 1) and J3 (operating in time period 1, 2 and 3) are operating. Similarly, the results can be interpreted for country 2 . The last column provides the total cost in each case. Firstly, the results are analysed by varying the capacity of the plant from 2000 to 400 while keeping warehouse capacity fixed. With decreasing the capacity, the total cost increases, and none of the plants are expanded till plant capacity is 1000. However, on further reducing 


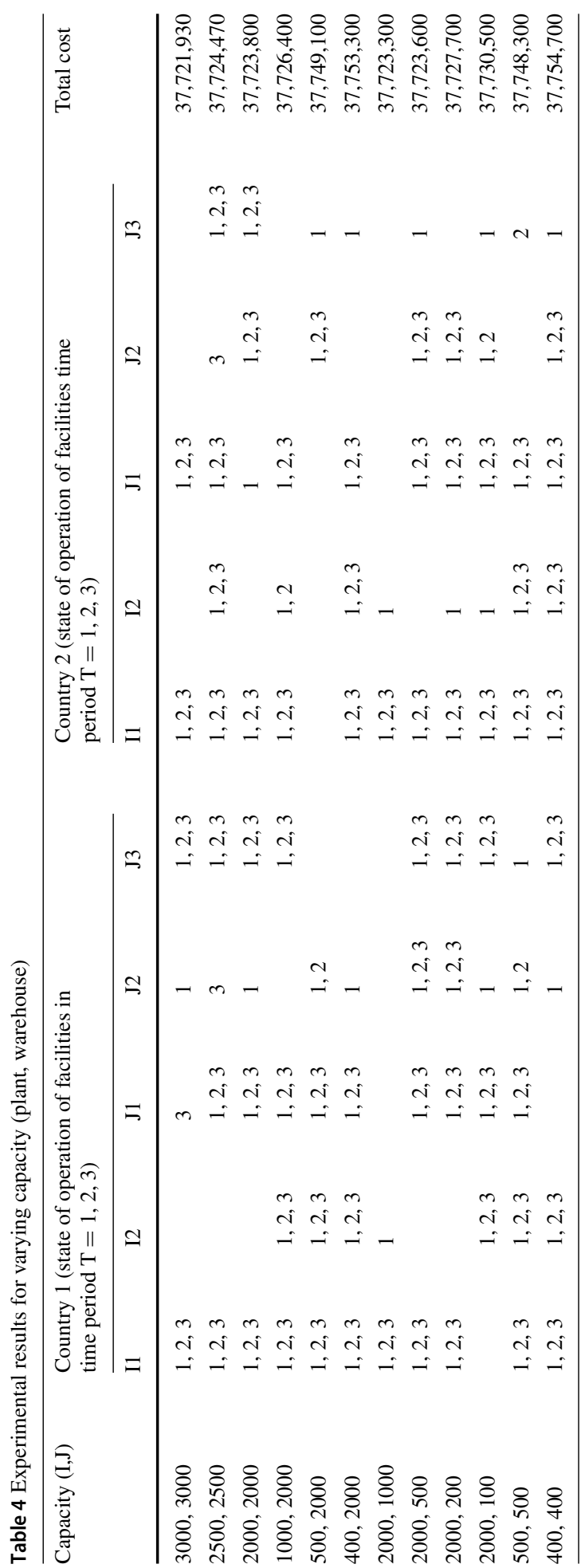




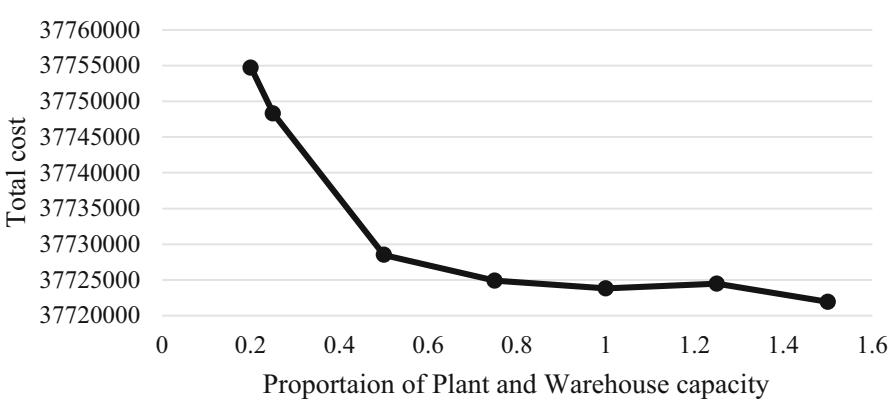

Fig. 3 Fluctuation in total cost with plant and warehouse capacity

the plant capacity to 500, plants (I1, C1) and (I1, C2) require capacity expansion in T2 and T3 time period, respectively. Similarly, the results are investigated by varying the capacity of the warehouses while keeping the plant capacity fixed. In this case, also, the total cost increases as warehouse capacity is decreased, but the increment is smaller as compared to the plant capacity case. Further, the capacity of both plants and warehouses are varied together. Figure 3 provides the fluctuation in total cost with respect to the change in capacity from the base case. From Fig. 4 and Table 4, it is observed that when the capacity is decreased from the base case, total cost shoots up, and the number of plants and warehouses increases. When the capacity is increased from the base case, the total cost decreases. However, when capacity is 1.25 times the base case, the results are opposite. The possible reason for this may be that plant $(\mathrm{I} 2, \mathrm{C} 2)$ is operating in $\mathrm{C} 2$ and maybe exporting the products to country $\mathrm{C} 1$, thus, causing an increase in total cost.

The results are further investigated by varying the capacity of plants and warehouses. Previously, the capacities for all the plants and warehouses in both countries are taken the same. Further, to test the performance of the model for varying plant capacity, an experiment is conducted where the capacities of plant I1 and I 2 in $\mathrm{C} 1$ are taken as 500 and 200 respectively, and $\mathrm{I} 1$ and $\mathrm{I} 2$ in $\mathrm{C} 2$ are taken 500 and 600 respectively. The variation in plant capacities over time is depicted in Fig. 4a. It shows that the capacity of plant (I1, C1) expands in time period T2 and again expands in T3. However, plant I1, C2 and I2, C2 operate in constant capacity. A similar experiment is conducted for varying warehouse capacities where $\mathrm{J} 1, \mathrm{~J} 2$, and $\mathrm{J} 3$ have initial capacities 500, 300 and 100, and only $\mathrm{J} 1, \mathrm{~J} 2$ operate in $\mathrm{C} 2$ with initial capacities 300 and 200, respectively. Figure $4 \mathrm{~b}$ shows the capacity change of warehouses over time. It indicates that warehouse $\mathrm{J} 1, \mathrm{C} 1$ operates in only $\mathrm{T} 1$ time period whereas the capacity expansion for J2, C2 occurs in T3 time period. Thus, the proposed model well captures the dynamic nature of the facilities, which are re-evaluated and changed over time.

In addition to the above, remanufacturing and repairing costs have been analysed for different proportion of quantities remanufactured and repaired. For instance, the horizontal axis of Fig. 3 shows $10 \%$ to $90 \%$ labels where $10 \%$ means that out of total quantity returned at a warehouse from a market, $10 \%$ of that quantity is sent for remanufacturing whereas $90 \%$ of the returned products are reparable at warehouse/collection/repair centers. Similarly, $90 \%$ indicates out of total quantity returned at the warehouse, $90 \%$ of products cannot be repaired at the warehouse/repair center, and therefore, they require remanufacturing.

The total cost linearly increases with an increase in the percentage of remanufacturing. It can be visualized from Fig. 5 that moving from 10 to $90 \%$ case, the remanufacturing cost increases, whereas the repairing cost decreases subsequently. 


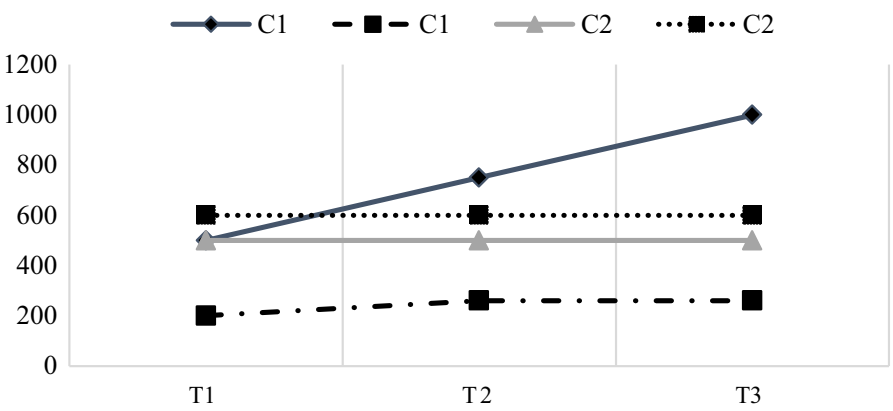

(a) Variation in plant capacity over time

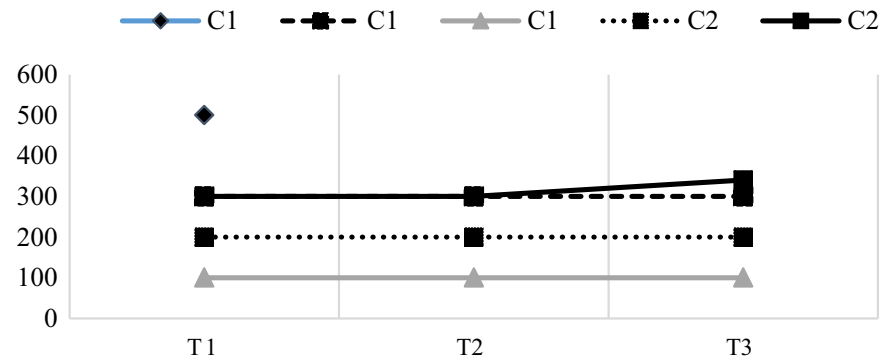

(b) Variation in warehouse capacity over time

Fig. 4 a Variation in plant capacity over time. b Variation in warehouse capacity over time

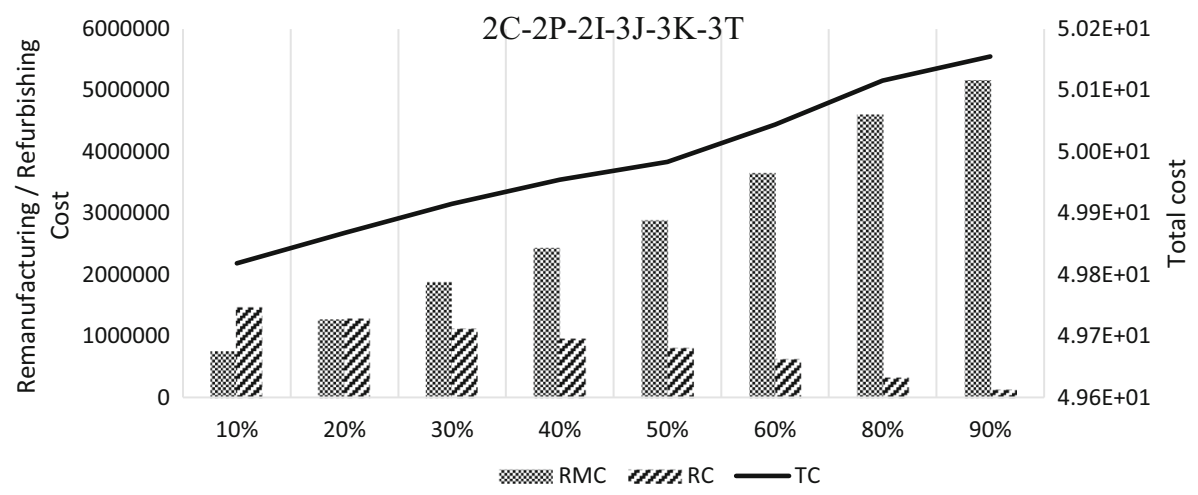

Fig. 5 Variation in remanufacturing, repairing, and total cost

\section{Implications}

\subsection{Managerial implications}

This paper discusses a dynamic facility network configuration model. The paper focuses primarily on reverse logistics under warranty returns. Furthermore, the model provides decisions regarding the capacity expansion of existing plants and warehouses and the establishment 
of new facilities. The proposed mathematical model assumes significance over the existing traditional models for closed-loop supply chain/reverse logistics because they focus only on the linear flow of the product, i.e., from the manufacturing plant to the market via the warehouse and, conversely, from the market to the warehouse to the plant in reverse flow. However, the proposed model is more significant than the existing models that focus on the unidirectional flow of the product. However, the product flow in the proposed model is also possible within plants and warehouses. For reverse logistics, the linear flow of the product is considered because the products returned from the market are examined for repair and then moved to plants for remanufacturing if repair is not possible. Thus, the proposed production-distribution network presents a transition from a linear to a circular economy. The proposed model is tested on different datasets ranging from two countries (2C) to five countries (5C) with different proportions of products that require repair and remanufacturing. The proposed MILP model provides an optimal solution for all the datasets in an acceptable computational time. However, for the $70 \%$ QRM case, high data complexity limits the solver from reaching an exact solution.

The proposed model helps decision makers optimally design a dynamic network configuration that is more robust and agile to address the dynamic global trade environment. The demand for a product does not follow the same trend throughout its life cycle. Therefore, the location decisions should be re-adjusted and updated according to the product demand. The consideration of post-sale services provides a cost saving opportunity to firms along with fulfilling their corporate social responsibility targets. The consideration of hybrid facilities with capacity flexibility is a novel addition to the existing production-distribution models. Capacity flexibility ensures the continuity of operations in the case of variable market demand. Thus, the proposed model can be used by academics and the industry community to explore the returns of products at the end of their useful life, their disposal and their re-sale in secondary markets.

\subsection{Theoretical and decision-support insights}

The paper provides a generic formulation for a global-level production-distribution network that also focuses on post-sale services. The model supports various configuration- and coordination-related decisions in the supply chain, such as facility allocation, production quantity, distribution of products, and capacity expansion. The hybrid facility network considered in the paper provides cost-saving opportunities to the firm. In addition, the global facility network enables experience and knowledge sharing, which helps to improve business performance. However, reverse logistics have been extensively explored in the manufacturing literature, and this paper provides a comprehensive MILP model considering the challenges of inter-country trade. The proposed model is analysed with respect to each country to devise a country-specific strategy. This comparative analysis of the operations in each country helps to benchmark countries within the firm and helps in relative performance improvement. The model considers the import/export cost, which helps in assessing and analysing the impact of different trade policies, for example, free trade agreements between countries or protectionist or moderate trade relations on the total cost. Furthermore, the inclusion of capacity expansion and dynamic facility locations ensures operational flexibility and helps to identify contingency plans in the case of disruptions. The proposed model also provides the optimal trade-off between the cost of capacity expansion or new facility requirements to accommodate product returns. The model can be used as a guideline for industrialists and academicians 
to explore the critical supply chain issues of carbon emissions, resilience, and end-of-life product disposal in the context of global facility network configuration.

\section{Conclusion and future scope}

The proposed MINLP formulation provides a well-structured network design model for forward and backward logistics considering multi-product, multi-period, and multi-country scenarios. The paper helps to determine a number of supply chain-related issues, such as the facility location, shipment size, and which facility to expand and how much to expand. The model optimizes the overall cost of the network, including the cost of repair, remanufacturing, trade tariffs, and the depreciation expense of machinery at the plant due to manufacturing/remanufacturing. The proposed model provides a generic framework that can be used to represent the reverse logistics network of any industry using its existing plants and warehouses for reverse logistics. Determining where to locate facilities and their capacities are the two crucial issues associated with any network configuration. In view of this, the proposed model determines the optimal facility locations, their operational status (active or closed), capacity requirements, and the optimal product distribution in the network.

The proposed model is tested with different datasets ranging from two countries to five countries. The proposed model is linearized and solved using an exact solution approach. For a better understanding, an explanation of $2 \mathrm{C}-2 \mathrm{P}-2 \mathrm{I}-3 \mathrm{~J}-2 \mathrm{~K}-3 \mathrm{~T}$ is provided. The results show that the demand in the current period and the existing capacity of the facilities are sufficient, and there is no need for facility expansion. Out of four plant locations, two plants operate in each country to manufacture products $\mathrm{P} 1$ and P2, respectively. In the same way, four out of six available warehouses are operating in period T1. The other types of product returns, such as end-of-life returns, are worth investigating in future studies. Moreover, the model experimentation with real data may provide some useful insights regarding the sensitivity of the parameters considered in the model.

Acknowledgements The authors would like to thank the Department of Science and Technology, Ministry of Science and Technology, New Delhi, India (IF170044), and University Grant Commission India-UKIERI (RP03411) for funding this research. 


\section{Appendix}

!objective function;

MIN $=$ @SUM $($ COU TIME $(\mathrm{C}, \mathrm{T}): \mathrm{OC}(\mathrm{C}, \mathrm{T})):$

! Fixed cost

@ F F R (COU TIME (C, T) | T\#EQ\# $1: F C(C, T)=\operatorname{eSUM}(\operatorname{PLANT}(\mathrm{I}): \mathrm{FPN}(I, C, T) * X(I, C, T)+F P E(I, C, T) * V(I, C, T)+V P E(I, C, T) * K 2(I$ $\left., C, T))+@ \bar{S} U M\left(\operatorname{WAREHOUSE}(\mathrm{J}): \operatorname{FWN}(\mathrm{J}, \mathrm{C}, \mathrm{T}) * \mathrm{Y}(\mathrm{J}, \mathrm{C}, \mathrm{T})+\mathrm{FWE}(\mathrm{J}, \mathrm{C}, \mathrm{T}) \star \mathrm{U}(\mathrm{J}, \mathrm{C}, \mathrm{T})+\operatorname{VWE}(\mathrm{J}, \mathrm{C}, \mathrm{T}){ }^{\mathrm{K}} \mathrm{K} 1(\mathrm{~J}, \mathrm{C}, \mathrm{T})\right)\right)$;

@EOR (COU_TIME (C, T) |T\#GE\#2:FC $(C, T)=@ S U M(P L A N T(I): F P(I, C, T) \star X(I, C, T)+F P N(I, C, T) * Z 1(I, C, T)+F P E(I, C, T) * V(I$, $\left.\mathrm{C}, \mathrm{T})+\operatorname{VPE}(\mathrm{I}, \mathrm{C}, \mathrm{T}){ }^{*} \mathrm{~K} 2(\mathrm{I}, \mathrm{C}, \mathrm{T})\right)+$

aSUM (WAREHOUSE $(J): F W(J, C, T)$ *Y $(J, C, T)+F W N(J, C, T) * Z 2(J, C, T)+F W E(J, C, T) * U(J, C, T)+V W E(J, C, T) * K 1(J, C, T)))$ : QFOR (PLA COU TIME (I, C, T) |T\#GE\#2:

$\mathrm{Z} 1(\mathrm{I}, \mathrm{C}, \mathrm{T})<=\mathrm{X}(\mathrm{I}, \mathrm{C}, \mathrm{T})$;

$\mathrm{ZI}(\mathrm{I}, \mathrm{C}, \mathrm{T})<=(1-\mathrm{X}(\mathrm{I}, \mathrm{C}, \mathrm{T}-1))$;

$\mathrm{Z} 1(\mathrm{I}, \mathrm{C}, \mathrm{T})>=\mathrm{X}(\mathrm{I}, \mathrm{C}, \mathrm{T})+(1-\mathrm{X}(\mathrm{I}, \mathrm{C}, \mathrm{T}-1))-1$

) ;

QFOR (WAR COU TIME (J, C, T) | T\#GE\#2:

$\mathrm{Z} 2(\mathrm{~J}, \mathrm{C}, \mathrm{T})<=\mathrm{Y}(\mathrm{J}, \mathrm{C}, \mathrm{T})$;

$\mathrm{Z} 2(\mathrm{~J}, \mathrm{C}, \mathrm{T})<=(1-\mathrm{Y}(\mathrm{J}, \mathrm{C}, \mathrm{T}-1))$

$\mathrm{Z} 2(\mathrm{~J}, \mathrm{C}, \mathrm{T})>=\mathrm{Y}(\mathrm{J}, \mathrm{C}, \mathrm{T})+(1-\mathrm{Y}(\mathrm{J}, \mathrm{C}, \mathrm{T}-1))-1$

)$;$

AFOR (PLA COU TIME (I, C,T) : $\operatorname{ABIN}(Z 1(I, C, T)))$

QFOR (WAR_COU TIME $(\mathrm{J}, \mathrm{C}, \mathrm{T})$ : @BIN $(\mathrm{Z} 2(\mathrm{~J}, \mathrm{C}, \mathrm{T})))$;

a FOR (PLA_COU_TIME ( I, C, T) | T\#EQ\# $1: \mathrm{V}(\mathrm{I}, \mathrm{C}, \mathrm{T})=0)$

(AFOR (WAR COU TIME ( J, C, T) |T\#EQ\# $1: \mathrm{U}(\mathrm{J}, \mathrm{C}, \mathrm{T})=0$ ) ;

! Production cost:

@FOR (COU TIME (C,T): PC (C,T) =@SUM (PRODUCT (P) : @SUM (PLANT (I): QP (P, I, C, T) *CP $(P, I, C, T))$ ));

@FOR (COU TIME $(C, T): \operatorname{RMC}(C, T)=$ @SUM (PRODUCT (P) : @SUM (PLANT (I) : @SUM (WAREHOUSE (J) : @SUM (MARKET (K) : QRM (P, K, J, I, $\left.\left.\left.\left.\mathrm{C}, \mathrm{T}){ }^{*} \mathrm{CR}(\mathrm{P}, \mathrm{I}, \mathrm{C}, \mathrm{T})\right)\right) 1\right)\right)$;

! Transportation cost:

a ) *T1 $(P, I, C, I 1, B, T))))$ ) +@SUM (PRODUCT (P) : @SUM (PLANT (I) : @ SUM (WAREHOUSE (J) : @ SUM (COUNTRY (B) : $Q 2$ (P, I, C, J, B, T) * $\mathrm{T} 2(\mathrm{P}, \mathrm{I}, \mathrm{C}, \mathrm{J}, \mathrm{B}, \mathrm{T}))))$ )

@SUM (PRODUCT (P) : @SUM (PLANT ( I) : @SUM (MARKET (K) : @SUM (COUNTRY (B): : 3 (P, I, C, K, B, T) *T3 (P, I, C, K, B, T) ) )) ) + @SUM (P RODUCT (P) : @SUM (WAREHOUSE ( $J$ ) : @SUM (WAREHOUSE (J1) :

@SUM (COUNTRY (B) : Q4 (P, J, C, J1, B, T) *T 4 (P, J, C, J1, B, T )) )) ) +@SUM (PRODUCT (P) : @SUM (WAREHOUSE (J) : @SUM (MARKET (K) : @SUM (COUNTRY (B) : Q $5(P, J, C, K, B, T) * T 5(P, J, C, K, B, T)))$ )) + @SUM (PRODUCT (P) : @SUM (WAREHOUSE (J) : @SUM (MARKET (K) : T7 $(P, K, C, J, C, T) \star Q R F(P, K, J, C, T)))$ ) +@SUM (PRODUCT (P) : @SUM (PLANT (I) : @SUM (WAREHOUSE (J) : @SUM (MARKET (K) : QRM (P, K, $J, I, C, T) * T 8(P, J, C, I, C, T))) 1))$;

! Import/export cost;

@FOR (COU TIME (C, T) : IE (C, T) =@SUM (PRODUCT (P) : @SUM (PLANT (I) : @SUM (PLANT (I1) : @SUM (COUNTRY (B) : Q1 (P, I, C, I1, B, T )$\star T 6(P, C, B, T))))$ ) + @SUM (PRODUCT (P) : @SUM (PLANT (I)

: $\operatorname{aSUM}(\operatorname{WAREHOUSE}(\mathrm{J})$ : @SUM (COUNTRY (B) : $Q 2(P, I, C, J, B, T)$ * T $6(P, C, B, T)))$ )) +@SUM (PRODUCT (P) : @SUM (PLANT (I) : @SUM (M ARKET $(K):$ @SUM (COUNTRY (B) : $\left.\left.\left.Q 3(P, I, C, K, B, T){ }^{\prime} T 6(P, C, B, T)\right)\right)\right)$ ) +@SUM (PRODUCT (P) : @SUM (WAREHOUSE (J) : @SUM (WAREHOU SE (J1) : @SUM (COUNTRY (B) : Q4 (P, J, C, J1, B, T) *T6 (P, C, B, T) )) )) +@SUM (PRODUCT (P) : @SUM (WAREHOUSE (J) : @SUM (MARKET (K )$:(\operatorname{SUM}(\operatorname{COUNTRY}(\mathrm{B}): \mathrm{Q} 5(\mathrm{P}, \mathrm{J}, \mathrm{C}, \mathrm{K}, \mathrm{B}, \mathrm{T}) * \mathrm{~T} 6(\mathrm{P}, \mathrm{C}, \mathrm{B}, \mathrm{T}))))))$;

! Depreciation expense;

@FOR (COU TIME (C, T) :DE (C,T) =@SUM (PRODUCT (P) : @SUM (PLANT (I) : DP (P, I, C, T) *QP (P, I, C, T) +@SUM (WAREHOUSE ( J) : @SUM $(\operatorname{MARKET}(\bar{K}): D R(P, I, C, T) * Q R M(P, K, J, I, C, T))))$ ));

! Holding cost

@FOR (COU TIME (C,T) : IH (C,T) = @SUM (PRODUCT (P) : @SUM (WAREHOUSE (J) :H (P, J, C, T) *IN $(P, J, C, T)))$ );

! Refurbišshing cost

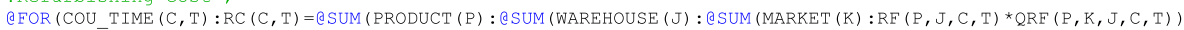
$1) 1 ;$

! Total cost:

a FOR (COU $\operatorname{TIME}(C, T): O C(C, T)=F C(C, T)+P C(C, T)+T C(C, T)+\operatorname{IE}(C, T)+D E(C, T)+I H(C, T)+R C(C, T)+R M C(C, T)) ;$

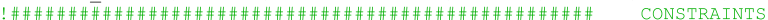

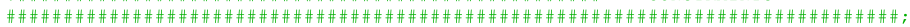

@FOR (COU TIME $(C, T)$ : @FOR (PRODUCT (P) : @SUM (MARKET $(K): R T(P, K, C, T))>=$ @SUM (MARKET (K) : @SUM (WAREHOUSE (J) : QRF (P, $\mathrm{K}, \mathrm{J}, \mathrm{C}, \mathrm{T})$ ) ) +@SUM (WAREHOUSE (J) : @SUM (PLANT (I) : @SUM (MARKET (K): QRM (P, K, J, I, C, T ) ) ) ) ) )

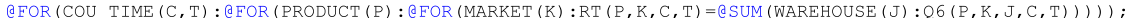

@FOR (PRO_WAR_COU_TIME $(P, J, C, T): @ F O R(M A R K E T(K): Q R F(P, K, J, C, T)+@ S U M(P L A N T(I): Q R M(P, K, J, I, C, T))=Q 6(P, K, J, C$ , T))

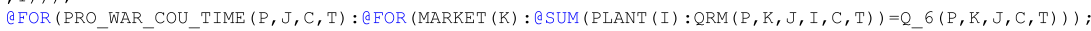

ONEPS $=0.99999$

QFOR (TCMW $(\mathrm{P}, \mathrm{K}, \mathrm{J}, \mathrm{C}, \mathrm{T})$ :

Q_ $6(P, K, J, C, T)>=.1 * Q 6(P, K, J, C, T)$;

Q_ $6(P, K, J, C, T)<=.1 * Q 6(P, K, J, C, T)+$ ONEPS ;

ब $\bar{G} I N(Q \quad 6(P, K, J, C, T))$; 
) ;

@EOR (PRO PLA COU TIME ( $, I, C, T): Q P(P, I, C, T)$ +@SUM (WAREHOUSE (J) : @SUM (MARKET (K) : QRM (P, K, J, I, C , T) )) $\operatorname{NM} 1(I, C, T) * 50000<=2000 * X(I, C, T)+\operatorname{aSUM}(P E R I O D(K) \mid K \# L E \# T: K 2(I, C, K)))$;

@FOR (PRO PLA COU TIME (P, I, C, T) : (QP (P, I, C, T) + @SUM (WAREHOUSE (J) : @SUM (MARKET $(K): Q R M(P, K, J, I, C, T)))$ ) - ( $1-$ $\operatorname{NM} 1(\mathrm{I}, \mathrm{C}, \overline{\mathrm{T}})) * \overline{5} 000 \overline{0}<=2000 * \mathrm{X}(\mathrm{I}, \mathrm{C}, \mathrm{T}))$;

@FOR (PLANT (I) : @FOR (COUNTRY (C) : @FOR (TIME (T) :K2 (I,C,T)<=UB (I,C) *V(I,C, T))));

@EOR (PRO WAR COU TIME (P, J C C T) : @SUM (PLANT ( $)$ ) : @SUM (COUNTRY (B) : Q2 (P, I, B, J, C, T) )) +@SUM (WAREHOUSE (J1) : @SUM ( COUNTRY $(\bar{B}) \mid \bar{B} \overline{\#} E Q \# \bar{C}$ \#AND\# J\#NE\#J1:Q4 (P, J1, B, J, C, T $))+$

@SUM (WAREHOUSE (J1) : @SUM (COUNTRY (B) IB\#NE\#C:Q4 (P, J1, B, J, C, T) )) + @ SUM (MARKET (K) : QRF (P, K, J, C, T ) ) -

$\operatorname{NM} 2(\mathrm{~J}, \mathrm{C}, \mathrm{T}) * 50000<=2000 * \mathrm{Y}(\mathrm{J}, \mathrm{C}, \mathrm{T})+\operatorname{eSUM}(\operatorname{PERIOD}(\mathrm{K}) \mid \mathrm{K} \# \mathrm{LE} \# \mathrm{~T}: \mathrm{K} 1(\mathrm{~J}, \mathrm{C}, \mathrm{K})))$;

@FOR (PRO_WAR_COU_TIME (P, J, C, T) : @SUM (PLANT ( I) : @SUM (COUNTRY (B) : Q2 (P, I, B, J, C, T) )) +@SUM (WAREHOUSE (J1) : @SUM ( COUNTRY (B) |B\#EQ\#C \#AND\# J\#NE\#J1:Q4 (P, J1, B, J, C, T ) ) ) +

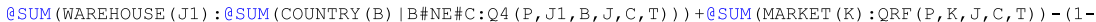

$\operatorname{NM} 2(\mathrm{~J}, \mathrm{C}, \mathrm{T})) * 50000<2000 * \mathrm{Y}(\mathrm{J}, \mathrm{C}, \mathrm{T}))$;

@FOR (WAREHOUSE (J) : @FOR (COUNTRY (C) : @ $\operatorname{EOR}(\operatorname{TIME}(\mathrm{T}): \mathrm{K} 1(\mathrm{~J}, \mathrm{C}, \mathrm{T})<=\mathrm{UA}(\mathrm{J}, \mathrm{C}) * \mathrm{U}(\mathrm{J}, \mathrm{C}, \mathrm{T})))$ );

!capacity constrint;

!Ensure plant/warehouse expanded can not be closed ;

$\mathrm{NT}=\mathrm{QSIZE}(\mathrm{TIME})$

@FOR (PLANT (I) : @FOR (COUNTRY (C) : @FOR (TIME (T): (NT-T+1)*V(I,C,T)<=@SUM (TIME (XM) |XM\#GE\#T:X(I,C, XM)))));

@FOR (WAREHOUSE (J) : @ FOR (COUNTRY (C) : @FOR (TIME (T) : (NT-T+1)*U (J, C, T) <=@SUM (TIME (XM) |XM\#GE\#T:Y (J,C, XM)) )) );

! Inventory Balance constraint;

@ $F$ FOR (COU TIME (C, T) : @FOR (WAREHOUSE (J) : @FOR (PRODUCT (P)।T\#EQ\#0: IN (P, J, C, T) =0)) )

@ $F O R$ (COU TIME (C,T) : @FOR (WAREHOUSE (J) : @ FOR (PRODUCT (P) | T\#EQ\#1: @SUM (MARKET (K) : @SUM (COUNTRY (B) : Q5 (P, J, C, K, B , T) )) + @SUM (WAREHOUSE (J2) : @SUM (COUNTRY (B) |B\#EQ\#C \#AND\#

J\#NE\#J $2: Q 4(P, J, C, J 2, B, T))$ ) +@SUM (WAREHOUSE (J2) : @SUM (COUNTRY (B) | B\#NE\#C: Q4 (P, J, C, J2, B, T) ) ) + IN (P, J, C, T) =@SU $M(\operatorname{PLANT}(\mathrm{I})$ : @SUM (COUNTRY (B) : Q2 (, , I , B, J, C , T) )) +@SUM (WAREHOUSE (J1) : @

SUM (COUNTRY (B) |B\#EQ\#C \#AND\#

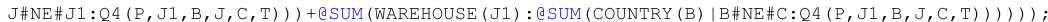

@FOR (COU_TIME (C, T) : @FOR (WAREHOUSE (J) : @FOR (PRODUCT (P) I T\#GE\#2:@SUM (MARKET (K) : @SUM (COUNTRY (B) : $Q 5$ (P, J, C, K, B ,T) ) ) + QSUM (WAREHOUSE (J2) : @SUM (COUNTRY (B) | B\#EQ\#C \#AND\#

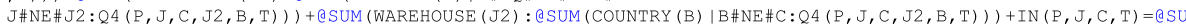
M(PLANT ( I) : @SUM (COUNTRY (B) : $Q 2(P, I, B, J, C, T)$ )) +@SUM (WAREHOUSE (J1) : @

SUM (COUNTRY (B) |B\#EQ\#C \#AND\#

J\#NE\#J1: Q4 (P, J1, B, J, C, T ) ) ) +@SUM (WAREHOUSE (J1) : @SUM (COUNTRY (B) |B\#NE\#C: Q4 (P, J1, B, J, C, T) ) ) + IN (P, J, C, T-

1))) ;

!Material balance at market;

@ $F O R$ (COU TIME (C, T) : @FOR (MARKET (K) : @FOR (PRODUCT (P) : QS (P, K, C , T) =@SUM (PLANT ( I) : @SUM (COUNTRY (B) : Q3 (P, I, B, K, $\mathrm{C}, \mathrm{T}))(+$

eSUM (WAREHOUSE (J) : @SUM (COUNTRY (B) : $Q 5(P, J, B, K, C, T)))$ )))

! Material balance at plant;

@FOR (COU_TIME (C, T) : @FOR (PLANT (I) : @FOR (PRODUCT (P) : QP (P, I, C, T) +@SUM (PLANT (I1) : @SUM (COUNTRY (B)|B\#EQ\#C

\#AND\# I\#NE\#II:Q1 (P, I $1, B, I, C, T)))+$

@SUM ( PLANT ( I 1) : @SUM (COUNTRY (B) |B\#NE\#C: $Q 1(P, I 1, B, I, C, T$ )) ) =@SUM (PLANT (I2) : @SUM (COUNTRY (B)|B\#EQ\#C \#AND\#

I\#NE\#I2:Q1 (P, I, C, I2, B, T) ) ) +

@SUM (PLANT (I2) : @SUM (COUNTRY (B) |B\#NE\#C: Q1 (P, I, C, I2, B , T)) ) +@SUM (WAREHOUSE (J) : @SUM (COUNTRY (B) : Q2 (P, I, C, J, B , T)) ) +@SUM (MARKET (K) : @SUM (COUNTRY (B):Q3(P, I, C, K, B, T) )) )));

! Returned product should be less than product distributed at market;

!Binary variables and integers;

@EOR (PRO_PLA_COU_TIME (P, I, C, T) :@GIN $(Q P))$;

@FOR (TCWP $(\mathrm{P}, \overline{\mathrm{K}}, \mathrm{J}, \overline{\mathrm{I}}, \mathrm{C}, \mathrm{T}): \operatorname{\Theta GIN}(\mathrm{QRM}))$;

@FOR (TCMW (P, K, J, C, T) : @GIN (QRF));

QFOR (PLA COU TIME (I, C, T) : @BIN $(X(I, C, T)))$;

@FOR (PLA COU ${ }^{-}$TIME $\left.(I, C, T): @ B I N(Z 1(I, C, T))\right)$

@FOR (WAR_COU_TIME $(\mathrm{J}, \mathrm{C}, \mathrm{T}): @ B I N(\mathrm{Y}(\mathrm{J}, \mathrm{C}, \mathrm{T})))$;

@EOR (WAR_COU_TIME $(\mathrm{J}, \mathrm{C}, \mathrm{T}): \operatorname{eBIN}(\mathrm{Z} 2(\mathrm{~J}, \mathrm{C}, \mathrm{T})))$;

@FOR (PLA_COU TIME $(I, C, T): @ B I N(V(I, C, T)))$;

@EOR (WAR COU TIME $(J, C, T)$ : $\operatorname{BBIN}(U(\mathrm{~J}, \mathrm{C}, \mathrm{T})))$ );

@ FOR (TCPP $(P, \bar{I}, C, I 1, B, T)$ : @GIN $(Q 1))$;

@FOR (TCPW (P, I, C, J, B, T) : @GIN (Q2));

@FOR (WAR_COU_TIME $(J, C, T): @ B I N(N M 2(J, C, T)))$;

QFOR (PLA_COU TIME (I, C, T) : @BIN (NM1 (I, C, T ) ));

@ FOR (TCPM (P, I, C, K, B, T) : @GIN (Q3));

@FOR (TCWW (P, J, C, J1, B, T) : बGIN (Q4)) :

@FOR (TCWM (P, J, C, K, B, T) : @GIN (Q5));

\section{References}

Abdallah, T., Diabat, A., \& Simchi-Levi, D. (2012). Sustainable supply chain design: A closed-loop formulation and sensitivity analysis. Production Planning \& Control, 23(2-3), 120-133.

Aldrighetti, R., Zennaro, I., Finco, S., \& Battini, D. (2019). Healthcare supply chain simulation with disruption considerations: A case study from Northern Italy. Global Journal of Flexible Systems Management, 20(1), 81-102.

Allied Market Research. (2019). Reverse logistics market to reach 603.9 billion dollars, globally by 2025 at 4.6\% CAGR. Retrieved March 24, 2020, from https://www.prnewswire.com/news-releases/reverselogistics-market-to-reach-603-9-bn-globally-by-2025-at-4-6-cagr-amr-300817572.html.

Amin, S. H., \& Baki, F. (2017). A facility location model for global closed-loop supply chain network design. Applied Mathematical Modelling, 41, 316-330. 
Bhatnagar, R., \& Viswanathan, S. (2000). Re-engineering global supply chains: Alliances between manufacturing firms and global logistics services providers. International Journal of Physical Distribution \& Logistics Management, 30(1), 13-34.

Business Strategy Report. (2015). The unexpected benefits of product returns. Retrieved March 24, 2020, from https://www.strategy-business.com/blog/The-Unexpected-Benefits-of-Product-Returns?gko=b808b.

Chen, Y. W., Wang, L. C., Wang, A., \& Chen, T. L. (2017). A particle swarm approach for optimizing a multi-stage closed loop supply chain for the solar cell industry. Robotics and Computer-Integrated Manufacturing, 43, 111-123.

Cognizant 2020 Insights. (2011). Reverse supply chain: Completing the supply chain loop. Retrieved March 24, 2020, from https://www.cognizant.com/whitepapers/reverse-supply-chain.pdf.

Cohen, M. A., \& Lee, H. L. (1988). Strategic analysis of integrated production-distribution systems: Models and methods. Operations Research, 36(2), 216-228.

Creazza, A., Dallari, F., \& Melacini, M. (2010). Evaluating logistics network configurations for a global supply chain. Supply Chain Management: An International Journal, 15(2), 154-164.

Dolgui, A., Ivanov, D., \& Sokolov, B. (2020). Reconfigurable supply chain: The X-network. International Journal of Production Research, 58(13), 4138-4163.

Dong, L., Kouvelis, P., \& Su, P. (2013). Global facility network design in the presence of competition. European Journal of Operational Research, 228(2), 437-446.

Du, F., \& Evans, G. W. (2008). A bi-objective reverse logistics network analysis for post-sale service. Computers \& Operations Research, 35(8), 2617-2634.

Erica, P. E. (2018). What stores do with $\$ 90$ billion in merchandise returns? The Wall Street Journal. Logistics report Feb, 2018. https://www.wsj.com/articles/what-stores-do-with-90-billion-in-merchandise-returns$1518777000 ? \mathrm{~ns}=$ prod/accounts-wsj.

Fleischmann, M. (2001). Quantitative models for reverse logistics (Vol. 501)., Lecture notes in economics and mathematical systems Berlin: Springer.

Ganji, E. N., Shah, S., \& Coutroubis, A. (2017). Sustainable supply and demand chain integration within global manufacturing industries. In 2017 IEEE international conference on industrial engineering and engineering management (IEEM) (pp. 1807-1811). IEEE.

Gianesello, P., Ivanov, D., \& Battini, D. (2017). Closed-loop supply chain simulation with disruption considerations: A case-study on Tesla. International Journal of Inventory Research, 4(4), 257-280.

Hosseini, S., Morshedlou, N., Ivanov, D., Sarder, M. D., Barker, K., \& Al Khaled, A. (2019). Resilient supplier selection and optimal order allocation under disruption risks. International Journal of Production Economics, 213, 124-137.

Ivanov, D. (2010). An adaptive framework for aligning (re) planning decisions on supply chain strategy, design, tactics, and operations. International Journal of Production Research, 48(13), 3999-4017.

Ivanov, D. (2020a). Predicting the impacts of epidemic outbreaks on global supply chains: A simulation-based analysis on the coronavirus outbreak (COVID-19/SARS-CoV-2) case. Transportation Research Part E: Logistics and Transportation Review, 136, 101922.

Ivanov, D. (2020b). Viable supply chain model: integrating agility, resilience and sustainability perspectives-Lessons from and thinking beyond the COVID-19 pandemic. Annals of Operations Research. https:// doi.org/10.1007/s10479-020-03640-6.

Ivanov, D., Das, A., \& Choi, T. M. (2018). New flexibility drivers for manufacturing, service, and supply chain systems. International Journal of Production Research, 56(10), 3359-3368.

Ivanov, D., \& Dolgui, A. (2020). Viability of intertwined supply networks: Extending the supply chain resilience angles towards survivability. A position paper motivated by COVID-19 outbreak. International Journal of Production Research, 58(10), 2904-2915.

Ivanov, D., Pavlov, A., \& Sokolov, B. (2014). Optimal distribution (re) planning in a centralized multi-stage supply network under conditions of the ripple effect and structure dynamics. European Journal of Operational Research, 237(2), 758-770.

Ivanov, D. A., Sokolov, B. V., \& Kaeschel, J. (2009). Structure dynamics control-based framework for adaptive reconfiguration of collaborative enterprise networks. International Journal of Manufacturing Technology and Management, 17(1-2), 23-41.

Ivanov, D., Sokolov, B., \& Kaeschel, J. (2010). Integrated supply chain planning based on a combined application of operations research and optimal control. Central European Journal of Operations Research, 19(3), 299-317.

Ivanov, D., Sokolov, B., \& Pavlov, A. (2013). Dual problem formulation and its application to optimal redesign of an integrated production-distribution network with structure dynamics and ripple effect considerations. International Journal of Production Research, 51(18), 5386-5403.

Ivanov, D., Tsipoulanidis, A., \& Schönberger, J. (2017). Global supply chain and operations management. A decision-oriented introduction to the creation of value. Berlin: Springer. 
Jerbia, R., Boujelben, M. K., Sehli, M. A., \& Jemai, Z. (2018). A stochastic closed-loop supply chain network design problem with multiple recovery options. Computers \& Industrial Engineering, 118, 23-32.

John, S. T., Sridharan, R., \& Kumar, P. R. (2017). Multi-period reverse logistics network design with emission cost. The International Journal of Logistics Management, 28(1), 127-149.

John, S. T., Sridharan, R., Kumar, P. R., \& Krishnamoorthy, M. (2018). Multi-period reverse logistics network design for used refrigerators. Applied Mathematical Modelling, 54, 311-331.

Kannan, D., Garg, K., Jha, P. C., \& Diabat, A. (2016). Integrating disassembly line balancing in the planning of a reverse logistics network from the perspective of a third party provider. Annals of Operations Research, 253(1), 353-376.

Kaya, O., Bagci, F., \& Turkay, M. (2014). Planning of capacity, production and inventory decisions in a generic reverse supply chain under uncertain demand and returns. International Journal of Production Research, 52(1), 270-282.

Kouvelis, P., Rosenblatt, M. J., \& Munson, C. L. (2004). A mathematical programming model for global plant location problems: Analysis and insights. IIE Transactions, 36(2), 127-144.

Liao, T. Y. (2018). Reverse logistics network design for product recovery and remanufacturing. Applied Mathematical Modelling, 60, 145-163.

Melo, M. T., Nickel, S., \& Da Gama, F. S. (2006). Dynamic multi-commodity capacitated facility location: A mathematical modeling framework for strategic supply chain planning. Computers \& Operations Research, 33(1), 181-208.

Min, H., \& Ko, H. J. (2008). The dynamic design of a reverse logistics network from the perspective of thirdparty logistics service providers. International Journal of Production Economics, 113(1), 176-192.

Mishra, S., \& Singh, S. P. (2019). An environmentally sustainable manufacturing network model under an international ecosystem. Clean Technologies and Environmental Policy, 21(6), 1237-1257.

Mishra, S., \& Singh, S. P. (2020a). Distribution network model using big data in an international environment. Science of the Total Environment, 707, 135549.

Mishra, S., \& Singh, S. P. (2020b). A stochastic disaster-resilient and sustainable reverse logistics model in big data environment. Annals of Operations Research. https://doi.org/10.1007/s10479-020-03573-0.

Mishra, S., Singh, S. P., Johansen, J., Cheng, Y., \& Farooq, S. (2019). Evaluating indicators for international manufacturing network under circular economy. Management Decision, 57(4), 811-839.

Nnorom, I. C., \& Osibanjo, O. (2008). Overview of electronic waste (e-waste) management practices and legislations, and their poor applications in the developing countries. Resources, Conservation and Recycling, 52(6), 843-858.

Ozceylan, E., Demirel, N., Çetinkaya, C., \& Demirel, E. (2017). A closed-loop supply chain network design for automotive industry in Turkey. Computers \& Industrial Engineering, 113, 727-745.

Pishvaee, M. S., Jolai, F., \& Razmi, J. (2009). A stochastic optimization model for integrated forward/reverse logistics network design. Journal of Manufacturing Systems, 28(4), 107-114.

Reddy, K. N., Kumar, A., \& Ballantyne, E. E. (2018). A three-phase heuristic approach for reverse logistics network design incorporating carbon footprint. International Journal of Production Research, 57(19), 6090-6114.

Shekarian, M., Nooraie, S. V. R., \& Parast, M. M. (2020). An examination of the impact of flexibility and agility on mitigating supply chain disruptions. International Journal of Production Economics, 220, 107438.

Srinivasan, S., \& Khan, S. H. (2018). Multi-stage manufacturing/re-manufacturing facility location and allocation model under uncertain demand and return. The International Journal of Advanced Manufacturing Technology, 94(5-8), 2847-2860.

Tan, W. J., Cai, W., \& Zhang, A. N. (2019). Structural-aware simulation analysis of supply chain resilience. International Journal of Production Research. https://doi.org/10.1080/00207543.2019.1705421.

Zhen, L., Sun, Q., Wang, K., \& Zhang, X. (2019). Facility location and scale optimisation in closed-loop supply chain. International Journal of Production Research, 57(24), 7567-7585.

Publisher's Note Springer Nature remains neutral with regard to jurisdictional claims in published maps and institutional affiliations. 